\title{
A theory of complex adaptive inquiring organizations: application to continuous assurance of corporate financial information
}

\author{
JOHN R. KUHN JR ${ }^{1}$, JAMES F. COURTNEY ${ }^{2}$ and BONNIE MORRIS ${ }^{3}$ \\ ${ }^{1}$ Crummer Graduate School of Business, Rollins College, 1000 Holt Avenue, Winter Park, FL 32789, USA; \\ e-mail: jkuhn@rollins.edu; \\ ${ }^{2}$ School of Accounting and Information Systems, College of Business, Louisiana Tech University, Louisiana, USA, \\ ${ }^{3}$ Palumbo Donahue School of Business, Duquesne University, Pennsylvania, USA
}

\begin{abstract}
Drawing upon the theories of complexity and complex adaptive systems and the Singerian inquiring system from C. West Churchman's seminal work The Design of Inquiring Systems, the study herein develops a systems design theory for continuous auditing systems. The discussion focuses on the two foundational theories, development of the theory of Complex Adaptive Inquiring Organizations (CAIO) and associated design principles for a continuous auditing system supporting a CAIO, and instantiation of the CAIO theory. The instantiation consists of an agentbased model depicting the marketplace for Frontier Airlines that generates an anticipated market share used as an integral component in a mock auditor going concern opinion for the airline. As a whole, the study addresses the lack of an underlying system design theory and comprehensive view needed to build upon and advance the continuous assurance movement and addresses the question of how continuous auditing systems should be designed to produce knowledge - knowledge that benefits auditors, clients, and society as a whole.
\end{abstract}

\section{Introduction}

The massive corporate frauds and the related bankruptcies of the late 1990s and early 2000s such as Enron, WorldCom, Adelphia, Parmalat, and others sent shock waves through the financial markets resulting in wide-spread concern over stronger corporate governance, improved internal controls, more transparent and timelier corporate reporting, and expansion of assurance activities particularly in the area of information technology controls over financial reporting. In the United States, the federal government intervened by passing the 'Public Company Accounting Reform and Investor Protection Act' (commonly referred to as the Sarbanes-Oxley Act or SOX) ${ }^{1}$. Many consider SOX the most significant corporate governance legislation since the securities laws passed in the 1930s (Hoffman \& Rowe, 2007). The Act highlights many of the inherent flaws of the corporate financial reporting process and the associated attestation framework. However, the Act does not address one major issue: the attestation timeframe. The traditional once a year audit of corporate financial statements hinders timely and relevant assurance reporting (Vasarhelyi \& Halper, 1991). The US Securities and Exchange Commission (SEC) recently passed a mandate

1 Although SOX is a US statute, it applies to all companies, domestic or international, traded on US stock exchanges. 
that all registrants (primarily public companies) report in the eXtensible Business Reporting Language (XBRL) format (Cox, 2008) that will, along with many other advantages, set the stage for continuous reporting and continuous assurance (CA). Similar efforts are taking place throughout the world. Spain, Denmark, and the United Kingdom, for example, now require the use of XBRL for tax or other mandatory financial filings.

CA of corporate financial information will require unique information systems (IS), referred to as continuous auditing applications/systems, to meet the needs of the assurers (public accounting firms) as well as other involved parties such as executive management of the organizations producing the financial statements, owners of these organizations, consumers, regulatory authorities, financial market participants, creditors, etc. These individuals and organizations in essence create a dynamic, connected network of actors that act/react to the behaviors of each other and the influences of external forces. For instance, environmental factors may affect the availability of key resources. The combination of drought in Australia, flooding in Europe, and the increased production of biofuels (farmers more interested in growing corn and soybeans rather than hops) have resulted in a shrinking supply of hops forcing beer breweries in Minnesota to find alternative and more expensive sources; experts predict some varieties of hops will increase in price by $400 \%$ and local beer prices may rise as much as $15-20 \%$ (Dyslin, 2007). CA systems therefore must be designed to support constantly changing environments, generate new knowledge, and provide decision support in an increasingly complex and connected world.

As a relatively new field, only minimal research has touched on the design of CA systems and the interaction of the various parties involved in and affected by the attestation process. Diverse views of and approaches to system design exist but, in general, many IS researchers consider system design as the central focus of the IS discipline (Markus et al., 2002). C. West Churchman (1971) considered design as a thinking process that involved the selection of an alternative from several possible alternatives in order to attain some goal and that design was an activity used to better the human condition (Parrish, 2008). As noted in the American Institute of Certified Public Accountants (AICPA) Code of Professional Conduct, the audit profession shares Churchman's view of serving humanity:

'Members should accept the obligation to act in a way that will serve the public interest, honor the

public trust, and demonstrate commitment to professionalism'. (American Institute of Public

Accountants, 2008)

This research study strives to address the lack of an underlying system design theory and comprehensive view in order to build upon and advance the CA movement. Broadly, can IS help auditors gain a better understanding of the complex environment in which their audit clients operate in order to properly opine on reported financial statements in a timely manner? More specifically (and the research question of this study), how should CA systems be designed to produce knowledge - knowledge that benefits auditors, clients, and society as a whole? To answer this question, we developed a comprehensive system design theory specifically for CA systems based on the theoretical underpinnings of complexity theory and the system requirements for Churchman's (1971) Singerian inquiring system (SIS). Subsequently, we instantiated this general model by creating an agent-based model (ABM) of the airline industry that includes agents representing a specific airline (the audit client), key competitors, consumers, the general economic environment, etc. Simulation results of the specific model facilitated analysis of the selected organization's ability to continue operations and can act as a decision aid for the auditor's assessment of this organization's ongoing viability — a requirement of generally accepted auditing standards.

The remainder of this research study consists of three distinct sections culminating with a discussion tying everything together and continues as follows. First, we present supporting background information and a review of related literature on CA/auditing, complexity theory, complex adaptive systems (CAS), and simulation and agent-based modeling. The next section examines the key tenets of Churchman's (1971) SIS, discusses how CAS theory and SIS can inform 
one another, and presents a set of design principles for knowledge management (KMS) and decision support systems (DSS) that support a Complex Adaptive Inquiring Organization (CAIO). The final section offers background information on the auditor's going concern opinion, details the design of an agent-based simulation model of the airline industry based on the CAIO organizational learning theory that can be developed into a CA application, and presents simulation results that are intended to support an auditor's going concern assessment of a particular client in the airline industry.

\section{Background}

\subsection{CA and continuous auditing}

The existing approach to auditing corporate financial statements contains two inherent flaws that have raised concerns in both academia and practice. The nature of the traditional attestation framework hinders timely and relevant assurance reporting (Vasarhelyi \& Halper, 1991). Performing an audit only once a year may result in fraudulent activity going undetected for up to a year or more and key stakeholders must wait an entire audit cycle to determine if the financial numbers released by an organization are correct in all material respects and that appropriate internal controls are in place to detect financial fraud. Critical decisions by investors, creditors, management, and others therefore may be determined from out-of-date information and conjecture rather than current, audited facts. This situation raises the risk of making less than optimal decisions.

Concerns over this weakness, in combination with the corporate frauds of the early part of this millennium, fostered the CA movement that many consider a viable approach to help identify potential audit concerns earlier in the process. The current SEC initiative for mandated continuous reporting of financial information and the focus of SOX on tighter internal controls over financial reporting and more transparency create an even stronger impetus to develop and implement CA functionality. CA can provide the external auditor a method of providing a more comprehensive, efficient, and effective audit by automating the testing of the full population of transactions for specific audit areas rather than evaluating only smaller samples due to the time constraints of manual processing. Boundless opportunities exist for researchers and practitioners alike to determine the optimal design, implementation approaches, and aftereffects of CA system use.

The environment in which organizations operate has become increasingly complex. Internal and external parties interact with one another creating a dynamic, connected network where the actions of one individual or organization can significantly affect the livelihood and behavior of others regardless of time and space dimensions. Auditors must be cognizant of this fact and consider the implications of external forces on their clients' operations. The remainder of this essay introduces the theories of complexity and CAS then discusses the techniques of simulation and agent-based modeling designed to analyze complex, organizational phenomena.

\subsection{Complexity}

Complexity, what does it truly mean? It depends on who you ask. The Merriam-Webster Online Dictionary defines the word as 'a whole made up of complicated or interrelated parts' (MerriamWebster Inc., 2008). This understanding held true until about 15 years ago (Laurent \& Koch, 1999) when a new, deeper interpretation emerged distinguishing complexity from complicated (Mikulecky, 1999; Reitsma, 2003). A complicated system (and the original view of complexity) can be completely and accurately described regardless of the number of individual components (Reitsma, 2003); 'complication is a quantitative escalation of that which is theoretically reducible' (Chapman, 1985). A complex system, on the other hand, cannot be fully understood by analyzing the components (Cilliers, 1998); the whole is greater than the sum of its parts where the dynamics of real systems arise from traits of the individuals and their environment (Siebers \& Aickelin, 2007). 
The core of complexity science lies in understanding the indirect effects that arise from the interactions of system components.

Collectively, complexity science and research have adopted the 'anti-reductionist' approach to analyzing phenomena as the dominant lens. Chapman (1985) argued that if the world can be explained in a reductionist manner then complexity is not qualitatively different from simplicity but merely quantitatively different. The main task for complexity science is to explain how relatively stable, aggregated, macroscopic patterns emerge from local interactions of numerous lower level entities (Srbljinovic \& Skunca, 2003). This notion of aggregate complexity underlies the theory of CAS that lies at the heart of this particular study. The next section delves further into CAS.

\section{$2.3 C A S$}

The theory of CAS arose from the complexity theories spawned in the natural sciences to develop mathematical models of systems in nature. Although considered one stream of complexity research, many variations of the definition and key premises of CAS exist. A quote from John H. Holland included in Waldrop (1993), one of the original researchers in the area, best depicts the general principles underlying CAS:

'A Complex Adaptive System is a dynamic network of many agents (which may represent cells, species, individuals, firms, nations) acting in parallel, constantly acting and reacting to what the other agents are doing. The control of a CAS tends to be highly dispersed and decentralized. If there is to be any coherent behavior in the system, it has to arise from competition and cooperation among the agents themselves. The overall behavior of the system is the result of a huge number of decisions made every moment by many individual agents'.

CAS examples include economies, social systems, ecologies, cultures, politics, technologies, traffic, weather, etc. (Dooley, 1997). In order to adequately comprehend and utilize a theory that spans such a wide array of disciplines with varied interpretations, Choi et al. (2001) developed a comprehensive framework of CAS elements and attributes depicted in Figure 1. The framework consists of three interacting and intertwined main foci each with a subset of additional components: (1) internal mechanisms, (2) co-evolution, and (3) environment. The remainder of this section on CAS briefly reviews these foundational concepts and principles in more depth as they represent the supporting lens for this study.

Agents represent the building blocks of CAS and are semi-autonomous units that seek to maximize some measure of goodness, or fitness, by evolving over time where fitness corresponds to the general well-being of the system. Giddens (1984) defined agency as the ability to intervene meaningfully in the course of events. Therefore, by definition, a system must include agents that

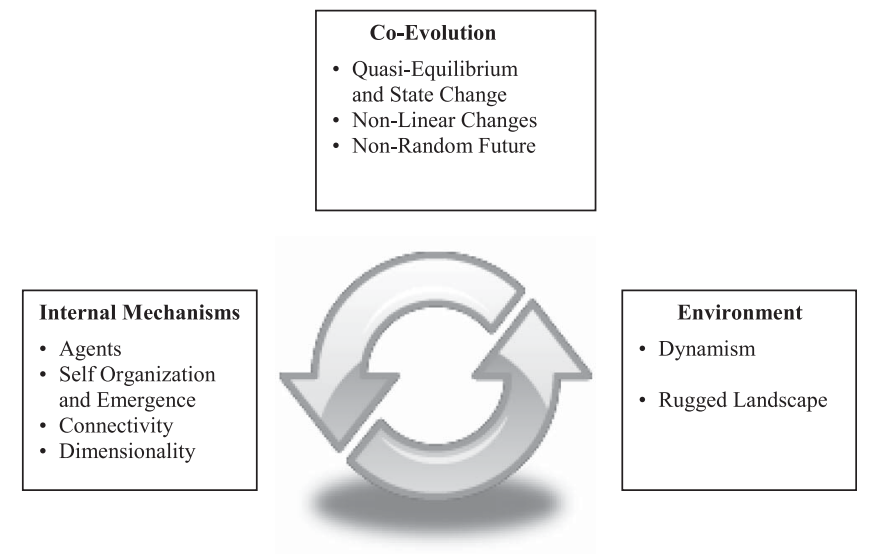

Figure 1 Underlying principles of complex adaptive systems. Adapted from Choi et al. (2001) 
can impact the state of the system by their actions in order to be considered a CAS - a definitive characteristic differentiating CAS from other types of systems. Examples of agents in a social CAS include individuals inside organizations, organizations comprising a profession, or even a profession operating in a global marketplace. The latter two illustrate a network of multiple CASs functioning in concert. Defining agents and CASs thus depends entirely upon the perspective of the observer.

CAS agents interact with other agents, both within their own system as well as with the environment which may include other CASs and their respective agents, commonly referred to as meta-agents (Benbya \& McKelvey, 2006). The exchange of information and resources between agents facilitate the generation of schema (Schein, 1992) defined as the norms, values, beliefs, and assumptions shared among the collective that dictate the manner in which agents interpret information and perform actions. Organizational leaders often declare formalized mission statements, create codes of conduct, ethics statements, etc. that represent core values and guide the behavior of agents, in particular, the interaction between employees and other stakeholders (e.g. customers, vendors, and other related parties).

Within the bounds of these 'rules of behavior' and shared values, agents strive to increase the fitness of their system, both locally and globally, by self-organization - the emergence of a pattern of order from a simple set of rules governing agent behavior in a connected network without the intervention of a central controller (Anderson, 1999; Luoma, 2006; Mason, 2007). The actions of agents can result in nonlinear impacts to the local system and network of systems depending on the connectedness of the system(s); a more connected system will generally experience larger ripple effects throughout as agents interact in a dynamic fashion. This symbiotic relationship facilitates co-evolution where multiple systems and/or sub-systems emerge together because 'there is feedback among the systems in terms of competition or co-operation and utilization of the same limited resources' (Zimmerman et al., 1998). The environment imposes changes on its members who react thus changing themselves and consequently changing the environment. Therefore, co-evolution occurs when system members are forced to adapt continually to the changing context wrought by others' strategies in order to remain relatively fit (Van Valen, 1973; Kim \& Kaplan, 2006).

Although the nature of a CAS prevents exact prediction of future actions and outcomes, distinct patterns of behavior exist underneath apparent randomness allowing examination and general predictive ability of most likely system states. In some cases small changes may lead to drastically different future paths; however, the same characteristic pattern of behavior emerges despite the change (Choi et al., 2001). Now that we have discussed the elements of the CAS theoretical foundation, the remainder of the section will describe ABM simulation, the primary research approach used to analyze CAS in the social sciences.

\subsection{Simulation and agent-based modeling}

As discussed previously, certain phenomena in nature and society are complex, dynamic, and impossible to break down into deterministic cause and effect relationships; no definable end point or optimal solution exists to problems in such contexts. Gaining insight, understanding, and knowledge of these events or happenings requires robust tools and technologies. Analytical models fail to adequately account for the indirect effects of CAS agent interactions. Computerbased simulation, on the other hand, offers the capacity and power to mimic real-world system behavior and observe changes in system states at any time rather than merely predicting the output of a system based on a set of inputs (Siebers \& Aickelin, 2007). The purpose of simulation is to better understand the inner workings of a system and/or to predict performance. Siebers and Aickelin (2007) compared simulation to an artificial white-room that allows one to gain insight but also to test new theories and practices without disrupting the actual system's operation. Troitzsch (2000) stated that if the theory framed for a particular system holds and the theory has been adequately translated into a computer model, then the simulation can assist in determining (1) what kind of behavior a target system will display in the future and (2) which state the target 
system will reach in the future. Such predictions involve analyzing trends rather than generating precise and absolute predictions of system performance (Siebers \& Aickelin, 2007); Keen and Sol (2007) referred to this as 'rehearsing the future'. Simulation, therefore, should be viewed as a decision support tool that requires consideration of the context of the real system before moving forward to implement steps intended to alter the system's direction and influence future state changes.

Agent-based modeling represents one type of stochastic simulation modeling that facilitates exploration of the nonlinear, adaptive interactions inherent to a CAS (Srbljinovic \& Skunca, 2003; Siebers \& Aickelin, 2007). The researcher specifies the rules of behavior at the micro-level for the individual agents and the interactions between agents. Structures then emerge at the macro-level due to the actions of these agents and their interactions with each other and the environment. The consequences at the macro-level that result from ABM many times are not obvious or expected. This discovered knowledge allows the interested party to identify potential system states that may not have been considered otherwise, thus enhancing the effectiveness of the decision making process. Cederman (1997) noted the following as some advantages of ABM: (1) the possibility of modeling fluid or turbulent social conditions when modeled agents and their identities are not fixed or given, but susceptible to changes that may include birth or death of individual agents, as well as adaptation of their behavior; (2) the possibility of modeling boundedly rational agents, making decisions and acting in conditions of incomplete knowledge and information; and (3) the possibility of modeling processes out of equilibrium.

Complexity researchers began using ABM in earnest in the 1990s (Epstein \& Axtell, 1996) and the approach has become a well-established simulation modeling tool in academia (Siebers \& Aickelin, 2007; Sklar \& Richards, 2010). As an example, an entire specialty in economics called Agent-Based Computational Economics (ACE) developed from the CAS movement to computationally study economies modeled as evolving systems of autonomous interacting agents (Tesfatsion, 2001). ACE attempts to understand why certain global regularities evolved and continue on in decentralized market economies despite the absence of a central controller (e.g. trade networks, currencies, and market protocols) and to examine the effects of alternative socio-economic structures on individual behavior and social welfare. Additional, related agentbased work continues by examining the evolutionary selection of forecasting heuristics (Anufriev \& Hommes, 2009) and knowledge encapsulation and discovery in market exchanges (Greenwood, 2007). As the gap between multi-agent system analysis/design and system implementation narrows, ABM is quickly becoming more commonplace in practice to solve real business problems such as examining customer behavior in a supermarket based on differing configurations of products in the store layout (Casti, 1997; Dastani \& Gomez-Sanz, 2005) and stakeholder (investors, market makers, and issuers) reactions to proposed changes to the tick size on the NASDAQ stock exchange (Bonabeau, 2002).

The underlying concepts of complexity science, CAS, and ABM hold true for ABM itself as a scientific tool. As current ABM researchers model complex phenomena, present their findings, and solve real world problems, more individuals will be convinced of the merits of ABM and begin to incorporate the approach in their own work which will increase exposure exponentially through a myriad of academic and professional networks. We fully expect ABM to continue a pattern of emergent behavior and growth for the foreseeable future. As Courtney et al. (2008) note, the need exists for a complex view of organizations and the stage is set for such a paradigm shift: ' $\ldots$ the science is there; the systems are there; the computational capacity is there. All that is lacking is the consciousness to apply them'.

In this background section, we present the supporting base for this study. First, the discussion on CA sets the stage for the practical setting of the study by detailing the origins and progression of the continuous audit movement. Next, the explanation of complexity science and CAS provides the theoretical foundation upon which the study relies. Finally, the discussion on simulation and agent-based modeling introduces the technical approach that will be applied. The next section integrates the key tenets of CAS with Churchman's SIS to develop the theory of CAIO. 


\section{Theory of CAIO}

Today, organizations face a completely new business environment than generations past - one that is complex, service-oriented, connected, global, in a constant state of flux, and built on individual and organizational knowledge. The knowledge-based view of the firm (Kogut \& Zander, 1992) contends that a valuable, rare, and inimitable resource (i.e. knowledge) can contribute to the competitive advantage of the individual/organization possessing it and performance will be reflective of that knowledge (Rodgers et al., 2008). In this new knowledge-based economy, interactions with customers and clients impact long-term success more so than ever and survival depends on the ability to explore new knowledge and maintain existing knowledge (Hall \& Paradice, 2005). However, decision makers' traditional knowledge sources and endowments may not be sufficient (Rodgers et al., 2008) to address problems that are more socially oriented and are thus considered semi- or unstructured. Commonly referred to as 'wicked' (Rittel \& Webber, 1973) or ill-structured problems (Mason \& Mitroff, 1973), these decision-making scenarios are highly uncertain, difficult to define, inextricably connected to their environment, and possess irreversible solutions. Such environments not only require organizations to be able to make decisions effectively and rapidly, but also be able to create knowledge and learn (Hall \& Paradice, 2005).

Courtney (2001) called for a new decision-making paradigm for DSS to adequately address wicked problems in complex contexts. Drawing upon unbounded systems thinking (Mitroff \& Linstone, 1993), SIS (Churchman, 1971), and the notion of 'inquiring organizations' (Courtney et al., 1998) the author introduced an alternative approach to the technical perspective in DSS research. The new paradigm brings in the perspectives of many stakeholders in order to provide greater insight into the nature of the problem, relationships among the connected elements in the wicked system, possible solutions, and downstream effects of implementing various solutions. Knowledge from any discipline or profession may be included as needed to assist in understanding the problem. Courtney (2001) illustrated the proposed DSS paradigm with an analysis of the decision-making process for planning and constructing a city's infrastructure. As noted, the process almost defies analysis with the countless internal departments and external parties involved, yet is ongoing and vital to every city in the world. These types of problems require and need DSS research that truly reflects the nature of the decision-making environment.

Recently, a stream of research has materialized examining information systems development (ISD) from a social constructivist lens where IS and their requirements emerge from the interaction of multiple stakeholders' views and knowledge is created (Avison et al., 1998; Markus et al., 2002; Richardson \& Courtney, 2004; Carugati, 2008). Carugati (2008) extends previous ISD literature by integrating Churchman's (1971) inquiring systems into a framework that maps various ISD activities on systems for the creation of knowledge. Applying the framework, the author examines ISD activity and knowledge creation at the micro-level where actors (i.e. agents) are involved in a continuous back-and-forth exercise between long-term planning (i.e. interacting with external networks) and day-to-day work activities (i.e. acting at the local level) concluding that adding an epistemological view of micro-level ISD activities allows for a better understanding of the situation, better prediction of success or failure, and ultimately better management of the ISD process.

This study answers Courtney's (2001) call for DSS research that considers the complexity and connectedness of the real business environment that organizations face in a knowledge-based economy by examining the micro-level (local) activities of network agents. The next section discusses Churchman's (1971) SIS that, combined with CAS, provide the theoretical foundation for the notion of a CAIO that underlies the system design principles developed for KMS and decision support. We then conclude with a discussion of the theory's implications for KMS and DSS research.

\subsection{Churchman's SIS}

Organizations must learn, adapt, and manage knowledge in order to succeed in today's dynamic environment (Richardson et al., 2001). To accomplish that, organizations must be inquisitive. 
Churchman (1971) defined inquiry as an activity that produces knowledge and stated one must have the capacity and ability to adjust behavior to changing circumstances in order to be considered knowledgeable. In his seminal text The Design of Inquiring Systems, Churchman examined the epistemologies of five schools of philosophy from a general systems theory perspective to determine their suitability as the foundation for the design of inquiring computer systems. These inquiring systems have been proposed as theoretical models for the creation of learning or inquiring organizations (Courtney et al., 1998; Courtney, 2001; Linden et al., 2007). As such, Linden et al. (2007) in their review of Churchman's inquiring systems believed that the inquirers can form the basis for the design of organizational KMS and encouraged their use to further develop IS as a discipline. This study answers that call.

Churchman named one of the inquiring systems after the philosophical beliefs of his mentor, Edgar Singer. The SIS is above all teleological, a grand teleology with an ethical base (Churchman, 1971). The SIS aspires to reach a highly idealistic purpose, the creation of exoteric knowledge for everyone as opposed to esoteric scientific knowledge that becomes relevant to an increasingly smaller audience as it is refined. The system seeks this knowledge in such a way as to take human and environmental considerations into account by choosing the right means for a broad spectrum of society. The SIS views the world as a holistic system in which everything is connected to everything else. Complex social and managerial problems must be analyzed as wholes (Mitroff \& Linstone, 1993) and may require knowledge from any domain, discipline, or profession to solve; reductionism inhibits the solution to such problems.

The SIS is based upon metrology, the science of measurement. Measuring in the system requires cooperation concerning the rules for measuring and agreement on units and standards in order to ensure the ability to replicate - the results agree within an acceptable level of refinement. The refinement process continues by partitioning the measurement process until the readings disagree (i.e. pushing back the decimal places), at which point progress can be made. Variables are 'swept in' to explain the discrepancy. By bringing in information from any source to improve its image of the world including varied perspectives or worldviews of a problem, this process represents one of the most holistic aspects of the SIS (Richardson et al., 2001). Mitroff and Linstone (1993) stated these perspectives bring to the forefront human beings collectively and individually in all their complexity. Because of the need for cooperation and a holistic view, the SIS has no primary authority built into the system. Every participant possesses authority, no single executive exists.

Refinement alone does not necessarily induce change and adaptation. The most dramatic changes occur when the need arises to revise assumptions. Churchman referred to this as the 'heroic mood' necessary to slay the 'status quo dragon'. To achieve such a state, the SIS uses a Hegelian dialectic process where the thesis and antithesis work simultaneously to determine the truth. The thesis defends the status quo of an existing paradigm while the antithesis proposes radical change questioning the quality of the status quo. Members of the community are both the observers of the debate as well as the participants. Ultimately, the community reaches a synthesis and the process of seeking new knowledge then continues on. Analyzing this process, Richardson et al. (2001) stated revolutionary change cannot be measured quantitatively and some of the most important measures in the SIS (exoteric knowledge, cooperation, diffusion of authority, and ethical purpose) may only be measurable qualitatively. Overall progress of an SIS should be measured by the extent to which the client, decision maker and designer become the same, that is, involves all of humanity, perhaps even those humans who are no longer living or are yet to be born (Linden et al., 2007).

Early in the book Churchman (1971: 43) lays out nine characteristics deemed necessary for something to be called a system. Later (p. 200) he applies these to Singerian inquirers Here we describe these and illustrate them with Wikipedia, which demonstrates many of an SIS's elements.

1. The system has the purpose of creating knowledge, which means creating the capability of choosing the right means (in the moral sense of right) for one's desired ends. Wikipedia does not create knowledge directly, but fosters knowledge-sharing and enables knowledge creation. 
Contributors are ethically bound to enter only knowledge that has been scientifically validated or at least to indicate its level of known validity.

2. The system's measure of performance is the 'level' of scientific and educational excellence of all society. Studies that compare the educational systems of various countries attempt to measure this.

3. The client is humankind, that is, all human teleological beings. Wikipedia exhibits this characteristic to the degree that it tries to make scientific knowledge available in many languages to anyone with a computer and internet connection.

4. The components of the system have traditionally been disciplines unless the goal is exoteric knowledge that is relevant to everyone in every society. Wikipedia makes knowledge from many and diverse disciplines available to all who can access it.

5. The system has a cooperative environment with fuzzy boundaries necessary for cooperation. Cooperation is of paramount concern in Wikipedia and is evidenced by all who contribute and maintain it.

6. The decision makers are ideally everyone, the most important of which are the heroes. The heroes are those who are not satisfied with the status quo, but who dare to ask such questions as whether the earth is the center of the universe or whether gravity may not only cause the apple to fall to the ground but may also affect the relationship between celestial objects. Such heroes abandon the known world and wander off into the perhaps chaotic unknown but may make major contributions to knowledge as a result of their quest. Jimmy Wales, the founder of Wikipedia, exhibited this characteristic to a degree when he envisioned how the internet could be harnessed to share the knowledge of the world.

7. The designers are ideally everyone. Progress can be measured in terms of the degree to which the client, decision maker, and designer are the same. Anyone who access or might access Wikipedia is its client; anyone who contributes decides what to contribute and designs that contribution.

8. The designer's intention is to change the system so as to maximize its value to the client (everyone). Wales' intent seems to have been maximizing the value of knowledge to curiosity seekers across the glove.

9. There is a built-in guarantor that gives a sense of optimism. The Wikipedia community seems optimistic that it can maintain the truth of knowledge in the system even though some bits of 'knowledge' have been untrue on occasion.

A smattering of KMS and decision support research has incorporated Churchman's inquiring systems into system design and decision-making frameworks. Hall et al. (2003) and Hall and Paradice (2005) described the architecture of a learning-oriented KMS developed through the integration of the inquiring systems with Simon's (1996) decision-making model. Richardson et al. (2006) presented design principles for KMS based on an integration of SIS with Habermas's theory of communicative action. From a decision-making standpoint, Hall and Davis (2007) extended Mitroff and Linstone's (1993) technical, organizational, and personal perspective (TOP) model and Courtney's (2001) DSS paradigm in the development of a value-based decision-making model that encourages multiple value-based perspectives and mediates value conflicts. As Linden et al. (2007) propose, these efforts show the beginnings or, more appropriately, a revitalization of Churchman's inquirers as kernel theories for the design of organizational KMS. We now continue Churchman's legacy by integrating the core concepts of SIS and CAS theory to present the design principles for a CAIO.

\subsection{Design principles for a continuous auditing system to support a CAIO}

As can be seen in the previous discussions, CAS theory and Churchman's (1971) SIS share many characteristics. This section delves further by comparing and contrasting the two types of systems (summarized in Table 1) then discusses how they can inform one another to offer a new, 
Table 1 Characteristics of the complex adaptive inquiring organization

\begin{tabular}{|c|c|c|c|}
\hline Characteristic & $\begin{array}{l}\text { Complex adaptive } \\
\text { system }\end{array}$ & $\begin{array}{l}\text { Singerian inquiring } \\
\text { system }\end{array}$ & $\begin{array}{l}\text { Complex adaptive } \\
\text { inquiring organization }\end{array}$ \\
\hline Nature of system & Teleological & Teleological, ethical & Teleological, ethical \\
\hline Purpose & To evolve and survive & $\begin{array}{l}\text { To create exoteric } \\
\text { knowledge }\end{array}$ & $\begin{array}{l}\text { To evolve and survive by } \\
\text { creating and sharing } \\
\text { exoteric organizational } \\
\text { knowledge }\end{array}$ \\
\hline Measure of performance & $\begin{array}{l}\text { Ability to adapt to } \\
\text { dynamic environments } \\
\text { (co-evolution) }\end{array}$ & $\begin{array}{l}\text { Level of scientific and } \\
\text { educational excellence } \\
\text { of all society }\end{array}$ & $\begin{array}{l}\text { Ability to adapt to } \\
\text { dynamic environments } \\
\text { by applying exoteric } \\
\text { organizational } \\
\text { knowledge }\end{array}$ \\
\hline Client & Networked agents & All humankind & $\begin{array}{l}\text { The organization and its } \\
\text { stakeholders }\end{array}$ \\
\hline Environment & $\begin{array}{l}\text { Self-motivated, self- } \\
\text { organized }\end{array}$ & Cooperative & $\begin{array}{l}\text { Self-motivated and self- } \\
\text { organized, but } \\
\text { cooperative }\end{array}$ \\
\hline Process and control & $\begin{array}{l}\text { Nonlinear; no controller } \\
\text { or executive; agents } \\
\text { interact to } \\
\text { spontaneously generate } \\
\text { new internal structures } \\
\text { and forms of behavior }\end{array}$ & $\begin{array}{l}\text { Nonlinear; no controller } \\
\text { or executive; variables } \\
\text { 'swept-in' as necessary } \\
\text { for revisions to adjust } \\
\text { readings }\end{array}$ & $\begin{array}{l}\text { Nonlinear; no controller } \\
\text { or executive; agents } \\
\text { interact to } \\
\text { spontaneously generate } \\
\text { new internal structures } \\
\text { and forms of behavior; } \\
\text { variables 'swept-in' as } \\
\text { necessary for revisions } \\
\text { to adjust readings }\end{array}$ \\
\hline Decision makers & $\begin{array}{l}\text { Internal agents; } \\
\text { decisions based on } \\
\text { local, simple rules }\end{array}$ & $\begin{array}{l}\text { Everyone, most } \\
\text { importantly 'heroes'; } \\
\text { focus on ethical } \\
\text { behavior }\end{array}$ & $\begin{array}{l}\text { Organizational members } \\
\text { and stakeholders }\end{array}$ \\
\hline Designers & Internal agents & Everyone & $\begin{array}{l}\text { Organizational members } \\
\text { and stakeholders }\end{array}$ \\
\hline Designer intention & $\begin{array}{l}\text { Maximize system value } \\
\text { to agents }\end{array}$ & $\begin{array}{l}\text { Maximize system value } \\
\text { to everyone }\end{array}$ & $\begin{array}{l}\text { Maximize system value } \\
\text { to organizational } \\
\text { members and } \\
\text { stakeholders }\end{array}$ \\
\hline Operating mode & Stable or chaotic & Normal or heroic & Normal or heroic \\
\hline Nature of change & Emergence & Emergence & Emergence \\
\hline
\end{tabular}

enlightened theoretical approach to the design of organizational KMS and DSS. The design principles developed and presented in Table 2 adhere to Churchman's (1971) conditions for a system and are intended to support decision making in a complex, connected organization facing complex, wicked problems.

\subsubsection{Nature and purpose of the system}

Churchman's (1971) first system requirement relates to the nature of a system. In order to be considered a system, something must be teleological (i.e. goal seeking) and consist of interrelated components that work together toward a common goal. Both a CAS and SIS exhibit teleological properties. A CAS seeks some overall goodness of fit for the networked system members (i.e. agents); survival is essential. An SIS strives to create exoteric knowledge for all humankind and implies the ability to know how to act in a specific situation, both from a procedural standpoint and an ethical manner. As Richardson et al. (2001) noted, ethical concerns are receiving increasing attention in IS and KMS research. All parties involved in the design, development, and use of 
Table 2 Design Principles for a continuous auditing system to support a CAIO

1. The system must consist of knowledge-seeking, learning, cooperative agents who advance the relative position and fitness of the organization in an ethical manner.

2. A system agent must be able to adapt to changes in the state of the external environment while, at the same time, increasing the overall knowledge level of an organization, its members, and connected systems.

3. Design of the system must include input from and consideration of the goals for all salient stakeholders.

4. The system must allow agents to interact with one another.

5. The system must have the ability to support agents with many different perspectives.

6. The system must have the ability to project future system states in order to facilitate decisionmaking of complex problems. The behavior of the application system emerges from the interactions of its many and varied agents.

$\mathrm{CAIO}=$ Complex Adaptive Inquiring Organizations

systems in a CAIO must be cognizant of and respond appropriately to the ethical issues facing an organization and its members. The first two system design principles are based on these presumptions:

Design Principle 1: The system must consist of knowledge-seeking, learning, cooperative agents who advance the relative position and fitness of the organization in an ethical manner.

\subsubsection{Environment and measures of performance}

The state of a CAS represents the compilation and interaction of system agents with one another and external environmental elements. Unlike an SIS where system members are cooperative and wish to align their individual goals to complement each other, CAS agents are generally selfmotivated and self-organized working from a simple set of local rules. A CAS succeeds merely by staying in existence - co-evolving with a dynamic environment by adapting to changes forced upon it by the environment and subsequently exacting change back on to the environment. The measure of performance for an SIS, on the other hand, is the level of scientific and educational excellence achieved for all society (Churchman, 1971) which Richardson et al. (2001) aptly noted does not yet exist. The next system design principle originates from these concepts:

Design Principle 2: A system agent must be able to adapt to changes in the state of the external environment while, at the same time, increasing the overall knowledge level of an organization, its members, and connected systems.

\subsubsection{Client, designer, and decision maker}

An SIS strives to integrate the perspectives of the system client, designer, and decision maker ultimately to a state where they become one: all humankind. Such a worldview implores ethical considerations in the design, development, and use of IS as the IS affects the level of knowledge for all humans. Although a lofty goal, this idealistic view defies practicality. To some extent, however, the like-mindedness of the three roles can be an achievable goal within a limited sphere of influence throughout a system. The bounds of the problem must be set to include only the most salient stakeholders (Mitchell et al., 1997; Richardson et al., 2001) which, for a CAS, includes internal agents and certain tightly coupled environmental elements and connecting CASs.

Ignoring the connectedness of systems runs the risk of system rejection and/or deleterious, unintended effects. For example, the modernization efforts of the Greek social security organization IKA in the 1980s and 1990s to develop and implement IS innovations failed miserably, not because of the technical capabilities of the systems (which were far superior) but rather due to the user community reflecting upon the way their actions impacted themselves and others in their 
social context (Avgerou \& McGrath, 2007). IKA employees reflected upon the ethical repercussions of their actions at both the local level and within the immediate sphere of networks and determined they could not, in good conscience, proceed using the systems. The users (i.e. the client), designers, and decision makers failed to work as one toward a common goal. The notions of a converged perspective, ethicality, and tightly coupled systems lead to the following system design principle:

Design Principle 3: Design of the system must include input from and consideration of the goals for all salient stakeholders.

\subsubsection{Operating mode, process and control, and nature of change}

As previously noted, both a CAS and SIS consist of many system agents interacting with one another and the state of these systems emerges over time through nonlinear agent interaction and cannot be undone; no single controller or executive exists that determines overall system direction. The primary difference in system operations between CAS and SIS stems from agent intention. CAS agents focus on maximizing their local goodness of fit that, together, spontaneously (i.e. chaotically) generates new structures and forms of behavior. The system vacillates between a stable and chaotic state. SIS agents, on the other hand, work together toward common goals by 'sweeping in' the perspectives of everyone to generate a consensus. The system resides in either a normal state or one referred to as 'heroic' where the hero wanders around lost, not knowing what to do but somehow finally finds his way-in essence, chaotic. Churchman (1971) likens this state to a hero in mythology who goes on a quest but is constantly blown off course by storms or battles. Finally, the hero finds his way and successfully accomplishes the goal of saving society. The nature of system operations for CAS and SIS generate the final set of system design principles:

Design Principle 4: The system must allow agents to interact with one another.

Design Principle 5: The system must have the ability to support agents with many different perspectives.

Design Principle 6: The system must have the ability to project future system states in order to facilitate decision making of wicked problems. The behavior of the CAIO emerges from the interaction of its many and varied agents.

The CAIO represents the next theoretical model of KMS systems for decision making in learning organizations, an answer to Courtney's (2001) call for a new DSS paradigm to address wicked problems in complex contexts. The design principles presented for CAIO systems are grounded in CAS theory and Churchman's (1971) SIS to offer guidance on the approach to creating holistic, ethical KMS that support decision making in a complex, connected environment. Next, we apply these principles to develop an illustrative simulation for the external auditor's going concern opinion that can be potentially developed as a CAS application and discuss current methods and procedures for evaluating the effectiveness and appropriateness of agent-based simulation models.

\section{An instantiation of the CAIO theory}

The fourth section of this paper presents an approach developed as an illustration of the CAIO theory. The instantiation consists of an agent-based simulation model to assist with the auditor's going concern opinion of a low-fare airline, clearly a complex problem. The remainder of the section continues as follows. First, a brief discussion of the nature of design science is warranted followed by a description of the research problem. Next, we provide background information on the industry and company selected, details of the design specifications for the model derived from the CAIO design principles, explain the overall modeling philosophy, and present the types of agents and agent behavior. Finally, we explain the execution of the simulation model and analysis of the results. 


\subsection{Design science}

The CAIO system design principles developed in this study fall under the design science paradigm. Design science research is intended to both further the academic field and be relevant to practitioners through the rigorous creation of IS artifacts in the form of theories, constructs, methods, frameworks, or instantiations (Parrish, 2008) and is fundamentally a problem-solving paradigm (Hevner et al., 2004). Benbasat and Zmud (1999) argue that the relevance of IS research directly ties to the ability of practice to implement theories. This study adheres to the design science requirements of rigorousness and relevance by testing the CAIO organizational learning and KMS theory through the creation of an agent-based simulation model in the context of the auditor's going concern opinion. The simulation model represents an instantiation of the theory.

\subsection{The research problem}

Accounting regulation mandates that auditors assess the ongoing viability of every client's business operations and report any substantial doubt about a company's ability to continue as a going concern for a reasonable period of time in the issued audit report that accompanies the financial statements. The Statement on Auditing Standards No. 59 The Auditor's Consideration of An Entity's Ability to Continue As a Going Concern (SAS 59) requires auditors to gain an understanding and assess existing conditions that affect an organization, including those of others in the industry and the economy in general ${ }^{2}$. With the push by the SEC for continuous reporting, associated need for CA, and the quickness by which the state of an organization can change in today's environment, auditors will need to assess continuing operations on a more frequent basis than once a year.

Although not explicitly expected to predict future conditions or events, auditors historically have relied upon bankruptcy prediction models, most commonly the Altman (1968) Z-score model (Dugan \& Zavgren, 1988; Grice \& Dugan, 2001; Grice \& Ingram, 2001; McKee, 2003). Bankruptcy prediction poses a challenge to auditors as the identification of cause and effect relationships between factors that may cause or be related to bankruptcy and the actual occurrence of bankruptcy can be difficult (McKee, 2003), if not impossible in a complex and connected business environment. McKee (2003) examined 146 US public companies that filed bankruptcy during 1991-1997. Of those, the auditors only reported a going concern problem in $54 \%$ of the cases. Further confounding the situation, the models auditors employ contain inherent faults and rely on restrictive assumptions such as linearity, normality, and independence among predictor variables (Zhang et al., 1999). Grice and Ingram (2001) examined the accuracy of the Altman Z-score and Grice and Dugan (2001) reviewed the same for the Zmijewski (1984) and Ohlson (1980) models. Both studies determined all three models failed to transcend generalizability to industries and time periods outside those of the original samples when manufacturing firms dominated the landscape. The environment most definitely has changed and now consists of knowledge-based organizations and economies that require more holistic research approaches.

Not all auditors employ statistical modeling techniques to the going concern assessment. Some perform analytical procedures such as historical trend analyses on operating losses, working capital deficiencies, negative operating cash flow, and adverse key financial ratios. They augment these financial reviews with examination of operational factors (e.g. labor work stoppages and dependence on the success of particular projects) and external circumstances (legal proceedings, changes in legislation, loss of a principal customer or supplier, or a natural disaster). Through discussions with three partners from an international public accounting firm, each elaborated on

2 In this paper, we refer to US auditing standards and use a US company as our case study. However, assessment of whether a client remains a 'going concern' is not just a requirement for US auditors. In most countries, auditors are required to assess whether a client is a going concern and make appropriate disclosures when the future viability of the client is in question. 
the general firm guidance by stating that every client is unique and therefore factors may be weighted differently in their assessments from client to client. However, all three agreed the primary indicator of potential business distress relates to the ability to pay short-term debt so the level of working capital (current assets - current liabilities), operating losses, and cash from operations receive the most attention.

The next section applies the CAIO theory to develop an agent-based simulation model for the auditor's going concern opinion that takes into account external conditions and can be executed on a regular basis to obtain a more timely sense of the direction an organization may head (i.e. a CA application). The model is based on the operations and financial condition for Frontier Airlines, a low-fare airline that recently filed for bankruptcy protection.

\subsection{Construction of the model}

\subsubsection{The company}

Frontier Airlines, a low-cost and affordable airline established in 1994, operates primarily in a hub and spoke fashion connecting 49 US cities coast to coast, eight cities in Mexico, and two in Canada through their hub at Denver International Airport (DIA). They currently are the second largest jet service carrier behind United Airlines at DIA. In January 2007, the Department of Transportation officially designated the company as a major carrier (at least $\$ 1$ billion in annual revenue). During the years 2007 and 2006, Frontier increased its year-over-year capacity by $14.4 \%$ and $8.4 \%$, respectively, and also increased the volume of passengers by $14.7 \%$ and $12.9 \%$, respectively, outpacing their increase in capacity during both periods. This is no small feat given the recent turmoil in the airline industry due to rising fuel costs, tightening of access to credit, declining consumer demand, and bankruptcies and mergers of industry competitors. The company intends to continue its growth strategy by expanding to new markets and adding frequency to existing markets it believes are currently underserved. However, due to the company's lack of borrowing capacity under current lines of credit and lack of other borrowing facilities, Frontier must rely on existing cash and operating cash flows for current operations and future growth.

The nature of the airline industry (i.e. customer service orientation, responsibility to society, heavy regulation, and sensitivity to external forces) and business situation of Frontier offer an interesting subject area for complexity-oriented research that will be pursued through the design and execution of an agent-based simulation model. The design specifications, modeling approach, and details of the simulation model will now be presented.

\subsubsection{Design specifications}

Hevner et al. (2004) asserted that IS design theory should guide both researchers and practitioners. These 'kernel theories' are applied, tested, modified, and extended through experience, creativity, intuition, and problem solving capabilities of the researcher (Walls et al., 1992; Markus et al., 2002). As such, this study proceeds from the theory building stage to theory testing and refinement through construction of a simulation model, the IS artifact. The CAIO theory informs the design specifications for the model as summarized in Table 3.

\subsubsection{Overall modeling philosophy}

4.3.3.1 Realism versus simplicity. The design and analysis of simulation models can range from the very specific to the very general and can be grounded in different combinations of theory and empirical data (Brenner \& Werker, 2007). Brenner and Werker (2007) presented an informative taxonomy of the various methods of building and analyzing simulation models as noted in Appendix A. Complexity researchers hotly debate and discuss the merits of these approaches, particularly on the dimension of realism (i.e. conventional, microsimulation, and history-friendly approaches) versus simplicity (Bayesian and abductive approaches). A number of researchers advocate the abductive approach that keeps the model as empirical as possible and as general as necessary yet allows the identification of underlying structural elements to explain observations 
Table 3 Design specifications

\begin{tabular}{l}
\hline \hline Design principle \\
\hline $\begin{array}{l}\text { The system must consist of knowledge-seeking, } \\
\text { learning, cooperative agents who advance the } \\
\text { relative position and fitness of the organization } \\
\text { in an ethical manner }\end{array}$
\end{tabular}

Specification

2. A system agent must be able to adapt to changes in the state of the external environment while, at the same time, increasing the overall knowledge level of an organization, its members, and connected systems

3. Design of the system must include input from and consideration of the goals for all salient stakeholders

The simulation will consist of consumers seeking services that meet their individual preferences and multiple airlines that attempt to gain market share through advertising toward those preferences

The users of the simulation (auditors and organizational management) work together to understand the potential impacts of interactions between the airline, consumers, and external elements on future states of the airline. The knowledge gained allows users to manage uncertainty and provide more accurate information about the ongoing viability of the organization - all in the best interests of organizational stakeholders Consumers' purchasing behavior will be dependent upon past purchasing behavior and past experiences. Airlines will adjust advertising based on consumer behavior as well as changes in general economic and other external factors. Both groups of agents will retain knowledge of past transactions in memory that will affect future behavior

The resulting number of passengers served on an annual basis as provided by the simulation will assist the auditors in their going concern opinion as well as offer insight into the inner workings of the economic system, creating knowledge for all salient stakeholders

Salient stakeholders in the airline include shareholders, organizational management, consumers, employees, trading partners, and auditors. Ongoing viability of the organization is critical to the future of all these groups. The simulation is designed to support the going concern assessment by the auditors in order to understand conditions that may have an imminent impact on the organization

4. The system must allow agents to interact with one another

Consumers, airlines, and external environmental elements interact in a mock economy

The individual agents in each group (consumer, airline, environmental) possess local decisionmaking rules and preferences

The simulated economy will provide an estimate of the number of passengers the airline will serve over the course of one year. This information will be vital to the determination of whether the organization faces the risk of business failure interactions of its many and varied agents 
The experiences of the Midgley et al. (2007) supermarket ABM led the research team to believe the emphasis of simulation modeling should be on minimalism: 'What are the one or two key aspects of consumer behavior that will explain $80 \%$ of the variance in purchases?'. In their opinion, the overriding goal should be the development of the simplest model that captures a substantial part of the actual phenomena. This study adopts the minimalist ABM design approach put forth by these researchers and supported by many others.

4.3.3.2 Agent design. The basic philosophy for agent design in the airline simulation model in this study consists of the notions of memory and decision rules, both necessary functionality for ABM. The consumer and airline agents possess the capacity to remember past experiences (i.e. KMS) and apply simple, local rules for considering and evaluating future opportunities. Consumers focus on personal consumption satisfaction while airlines concentrate on attracting the most passengers possible to increase operating profit and cash. Similar to the Midgley et al. (2007) supermarket retailer, airline agents exhibit larger memory capacity and more systematic decisionmaking capacities than consumer agents. Consumer decision timeframes vary from 1 week to a year based on the probability of travel derived from extant research of airline consumer traveling frequencies. After deciding to travel, consumers base purchase decisions on past purchasing behavior and related experiences. However, advertising by airlines may persuade some consumers to switch airlines (i.e. attract new customers) or solidify existing consumer loyalty. Airline agents conduct marketing decisions on a regular basis by analyzing current market share and environmental factors that affect the availability of capital.

4.3.3.3 Validation and verification. Simulation models, in essence, act as a surrogate for experimentation with the actual system (existing or proposed) that may be too costly or impractical (Law, 2005). Models that do not represent a 'close' approximation to the actual system naturally raise concerns about the appropriateness of any conclusions derived from model results. Therefore, model validation and verification are essential parts of the model development process (North \& Macal, 2007). Validation refers to whether the model represents and reproduces the behavior of the real-world system. On the other hand, verification focuses on the functionality and performance of the model. Was the conceptual model correctly translated into the computer program and does the model work as intended? North and Macal (2007) recommend periodic structured walk-throughs of the programming code to identify any errors. The designer verbally explains to an independent, knowledgeable audience how the model is supposed to function and then presents the code to see if it actually works as described.

For this particular study, we elected to validate and verify the airline simulation model based on some of the techniques advocated by North and Macal (2007). In order to validate the design of the model agents and their interactions/relationships, we discussed the initial set of assumptions about the airline industry with the Director of Financial Analysis Operations at a national airline and revised the assumptions accordingly. Appendix B lists the assumptions included in the final model. The director attended ABM training at the Argonne National Laboratory and therefore possessed both specific domain expertise as well as an understanding of the nature of ABM and simulation modeling.

We programmed the ABM in the visual editor of the Recursive Porous Agent Simulation Toolkit, commonly referred to as Repast Symphony. The visual editor allows the modeler to build decision trees similar to flowcharting that automatically creates underlying Java program code. To verify the Repast programming, we performed three distinct steps. First, we conducted a structured code walk-through of the ABM programming that consisted of the designer presenting the code to a 'fresh pair of eyes' (an independent coder) and manually tracing through examples of execution sequences. We performed this process with one of the ABM instructors at the Argonne National Laboratory in order to gain the necessary expertise level to adequately review the model's code. Second, we varied a number of the key parameters to extreme values in order to 'stress test' the model ensuring that the model did not produce unattainable results even under 
extreme circumstances. Finally, we executed the simulation on previous years' information for Frontier and compared the model's results to that of the actual performance by the company. This case approach addresses both the goals of verification and validation. In combination, these steps provide comfort that the model works as designed and produces accurate results within an acceptable range of values. The following section describes each type of agent in more detail.

\subsubsection{Types of agents and agent behavior}

4.3.4.1 Consumer agent properties. Harris and Uncles (2007) empirically examine a myriad of potential factors that affect airline consumer patronage-including behavioral, performance, promotional, and structural. The results indicate that past purchasing behavior (i.e. frequency of travel with a specific airline) and perception of airline performance (i.e. view of last experience) ranked highest in predictive ability for future purchases. Suzuki (2000) examines the relationship of airline on-time performance to market share noting that the level of satisfaction with the most recent experience can significantly affect future purchases, even for frequent flyers. Adhering to the minimalist abductive approach, the consumer agents in the model represent airline passengers that base their future purchases on past purchasing behavior and related experiences. For example, a consumer who has traveled Frontier Airlines seven times over the past 3 months is more likely to choose Frontier on the next purchase than a consumer who flew Frontier only once during that same timeframe. Furthermore, customers who encounter a low quality experience on their last Frontier flight will be more likely to switch airlines, particularly if the last prior experience with another airline was positive. Thus, frequent travel and high quality experiences act as anchors in consumer memory for future purchases. Consumer choice behavior in the model is therefore a function of four consumer agent properties that must be populated before executing the market simulation (i.e. Time 0):

1. Strength of Memory (1-9 rating).

2. Frequency of Travel ( $\%$ chance to travel).

3. Last Airline Chosen (Frontier, United, Other, None).

4. Last Trip Experience (Good, Bad, None) for each airline (Frontier, United, and Other).

The incorporation of Strength of Memory (SOM) and Frequency of Travel was facilitated by access to data from a recent study on airline consumer travel frequency conducted by the Cornell University School of Hotel Administration. We classified the SOM for consumer agents (as a percentage of total agents) as a 1-9 rating where 1 represents consumers who traveled only once in the past 3 months and 9 for those that traveled nine times or more over the same period. So, for example, in a model run consisting of 1000 consumer agents, the SOM property for 717 agents contained a value of 1,165 with a value of 2 , and so forth. These ratings will affect consumer behavior as discussed in the next section. As for the frequency property, consumers in the simulation determine whether or not to travel each week in the 52-week simulation (note: a single 'tick' in the model represents time passage of 1 week). The chance for each consumer to travel is also derived from the data in the Cornell study. For instance, consumers with a SOM rating of 1 only traveled once during the past 3 months (i.e. 12 weeks); therefore, the chance to travel in any individual week is $8 \%(1 / 12)$. Table 4 presents the nine SOM ratings and the associated chance to travel each week.

To determine the value of the last airline chosen property for each consumer agent, the model first calculates a random number from 0 to 100 then a random number for new travelers (i.e. no last airline), Frontier, and United to 'divvy up' the chances that the consumer agent will have flown a specific airline or not flown at all; the Other Airline category receives the remainder. In order to infuse some variability to avoid a deterministic model, the second calculation consists of a 10-point range around the 2006 market share percentage for the two airlines obtained from the collection of online databases administered by the Bureau of Transportation Statistics (BTS) with a $-2 \%$ adjustment to accommodate for the consideration of new travelers. For example, Frontier 
Table 4 Consumer travel frequencies

\begin{tabular}{llllll}
\hline \hline $\begin{array}{l}\text { Strength of } \\
\text { memory rating }\end{array}$ & $\begin{array}{l}\text { No. of times traveled } \\
\text { past 3 months }\end{array}$ & $\begin{array}{l}\text { Survey } \\
\text { responses }\end{array}$ & $\begin{array}{l}\text { Proportion of } \\
\text { respondents (\%) }\end{array}$ & $\begin{array}{l}\text { Proportion of } \\
\text { travelers (\%) }\end{array}$ & $\begin{array}{l}\text { Chance to travel } \\
\text { each week (\%) }\end{array}$ \\
\hline & None & 61207 & 67.39 & 0 & 0 \\
1 & One time & 21238 & 23.38 & 71.7 & 8 \\
2 & Two time & 4887 & 5.38 & 16.5 & 17 \\
3 & Three times & 1688 & 1.86 & 5.7 & 25 \\
4 & Four times & 770 & 0.85 & 2.6 & 33 \\
5 & Five times & 385 & 0.42 & 1.3 & 42 \\
6 & Six times & 267 & 0.29 & 0.9 & 50 \\
7 & Seven times & 148 & 0.16 & 0.5 & 58 \\
8 & Eight times & 118 & 0.13 & 0.4 & 67 \\
9 & Nine times & 118 & 0.13 & 0.4 & 75 \\
\hline \hline
\end{tabular}

earned the business of $18 \%$ of the travelers during 2006 for routes the airline serviced (Bureau of Transportation Statistics, 2008); therefore, the range for the chance that a specific consumer will have flown Frontier on the last trip randomly falls between $11 \%$ and $21 \%(16 \%+5 /-5)$. For new travelers, the random number calculation falls between $0 \%$ and $10 \%$. As an illustration of the process, assume the following occurs for the first consumer in the model: Last Airline random number $=75$, New Traveler $=5$, Frontier $=15$, and United Airline $=25$. The if $/$ then logic of the model to assign an airline (or none) as the last airline flown occurs in a sequence ending once a value has been assigned. The pseudo-code for this scenario would look like the following:

- If Last Airline rand num $<5$ Then Last Airline $=0$ else

- If Last Airline rand num $<20$ Then Last Airline $=1$ else

- If Last Airline rand num $<45$ Then Last Airline $=2$ else

- Last Airline $=3$

- End If

In this particular instance, the random number 75 causes an assignment of 3 for the last airline flown by this consumer agent.

Following assignment of the Last Airline property, the model determines whether the consumer agent experienced a good (value 0 ) or bad trip (value 1) by calculating a random number from 0 to 100 then comparing to the bad trip likelihood percentage (also a random number from 70 to 100). For instance, assume the model determines $75 \%$ of all travelers will experience a bad trip and then calculates a 60 as the random number used to determine the value for the Last Experience property. In this scenario, the consumer will have experienced a good trip with the last airline and thus, the value for Last Experience will be 0. Subsequently, the identical process occurs in order to set an experience value for the remaining two airlines. This holds true even if the consumer has not actually flown one or both of the airlines as the person may have predetermined opinions based on interaction with others in their personal network (i.e. friends, family, etc.). The visual editor and JAVA programming code can be viewed and downloaded from the publications list on the Repast website (http://repast.sourceforge.net/papers/papers_main.html). Now, on to consumer agent behavior.

4.3.4.2 Consumer agent behavior. Once consumers (and other agent types: airlines, environmental factors) receive the property assignments discussed in the previous section, the model simulation can commence. At Time 1 and each subsequent 'tick' representing the next week, the consumer 'decides' whether or not to travel based on the probabilities assigned to each consumer's Frequency of Travel property. Since new travelers have no previous flight experience they follow the same procedure for the assignment of Last Airline and Last Experience that existing travelers 
(i.e. they have flown before) encountered at Time 0 ; this occurs only when a new traveler chooses to travel for the first time. Existing travelers, after deciding to fly, the model reads whether Last Experience was good or bad. If good, then the traveler flies with the same airline and the Last Experience is updated for the current trip based on a random number compared against the bad trip likelihood percentage. On the other hand, if the Last Experience was bad, the model first identifies the SOM property value then continues on one of three distinct paths depending upon that value and will now be discussed.

We divided consumers into three groups based on the SOM: (1) 7, 8, 9 (very frequent travelers), (2) 4, 5, 6 (fly fairly often), and (3) 1, 2, 3 (fly less often). Consumers who fly very frequently typically are most likely to be enrolled in frequent flyer programs and have a stronger commitment to that specific airline; thus, they are not likely to switch airlines. The second group flies, on average, 1.3-2 times per month. Therefore, they too are very likely to be enrolled in frequent flyer programs and have a strong commitment to that specific airline but may be persuaded to switch airlines if the last trip was bad and/or they are exposed to airline promotional efforts (more detail provided in discussion of airline agents). For the final group, the model first looks at whether or not the Last Airline for the consumer advertised high during this week. If so, there is a greater likelihood that the consumer will have been exposed and persuaded to stay with the airline. If not, then the model examines the Last Experience for the other two airlines. If the consumer experienced positive trips for both other airlines, then the model randomly assigns one of the two as the airline the consumer now chooses to fly. If both past experiences on the other two airlines were not good, then the model will check to see if one was and the consumer will choose to fly that airline if true. If the consumer experienced bad trips for all three airlines, then the model will randomly choose to stay with the current airline or switch to one of the other two. The following discussion details airline agent properties and behavior.

4.3.4.3 Airline agents. The Airport Council International ranked DIA as the fifth busiest airport in the United States and 10th in the world serving 47 million passengers annually through 29 airline carriers, as obtained from the 2006 report provided by the Denver International Business Center (City and County of Denver, Colorado Municipal Airport System, 2006). United dominates the regional market with a 56.4\% share of 2006 passengers and Frontier, as a distant second, services $20.7 \%$. Twenty-seven airlines attract the remaining $22.9 \%$ with no single carrier serving more than $4.1 \%$. In this simulation, the airline agents consist of United, Frontier, and Others.

Due to the dependence on the DIA market as the sole hub and intense competition at that airport (and others) with United and other carriers, Frontier cannot raise prices to any significant degree to increase profit levels or offset unexpected and/or rising costs. Frontier management state in the 2006 annual report, 'Business and leisure travelers continue to reevaluate their travel budgets and remain highly price sensitive' (Frontier Airlines Holdings, 2006). For the 4-year period 2004-2007, the average fare ranged from a low of $\$ 102.31$ in 2005 to a high of $\$ 103.54$ in 2004, only a maximum swing of $1.2 \%$ over 4 years. Therefore, Frontier and other airline agents must entice consumers primarily through advertising efforts. The following excerpt from the 2006 annual report emphasizes the importance Frontier management places on advertising and brand awareness:

'Our sales efforts target value conscious leisure and business travelers. Value conscious customers are price-sensitive; however, we believe their travel decisions are also balanced with other aspects of our product offering such as our frequent flyer program, non-stop service, advanced seat assignments, service level and live television entertainment. In the leisure market, we offer discounted fares marketed through the Internet, newspaper, radio and television advertising along with special promotions and travel packages. In May 2003, we launched a new brand strategy and advertising campaign designed to identify Frontier as "A Whole Different Animal" and to set us apart from our competition. The campaign includes television, print and radio components that began running in the Denver market and have since expanded to additional markets along 
our routes. We have gathered extensive customer and employee feedback that has allowed us to identify elements of service that are important to our customers who have the potential to fly with us more often'. (Frontier Airlines Holdings, 2006)

In addition to the new branding campaign, Frontier also engaged in various sponsorship agreements including, but not limited to: the Colorado Avalanche hockey team, the Denver Nuggets basketball team, Colorado Rockies baseball team, etc. Advertising and promotions constituted $9 \%$ of total operating expenses in 2006. Clearly, advertising plays a large role in the success or failure of Frontier Airlines.

United Airlines entered bankruptcy proceedings on December 9, 2002 and eventually emerged on February 1, 2006. As expected, companies operating under the court's oversight must focus on managing costs. As a component of overall 2006 operating costs, advertising and promotion only comprised 6\% (United Air Lines, 2006). The report contained no specific income statement line item for these costs or any discussion of related expenses. Based on this lack of information, we assume United focuses their primary efforts on other areas and relies on their size, extensive flight availability, networks within the industry (e.g. partnership agreements with other airlines and travel agencies), and brand name to attract and retain customers. Therefore, the model places less emphasis on advertising for United.

As for the Other airlines category, the model contains no specific agent per se with. This category of airlines places a modicum of value on advertising levels in the consumer purchasing process and remains static. Only the Frontier and United agents evaluate environmental conditions (discussed later) and market share in order to adjust advertising levels.

The Frontier and United agents determine overall advertising levels initially at Time 0 then re-evaluate every 2 weeks (before the start of consumer purchases). Both agents first identify the environmental agent values: Fuel Cost (high/low), Regulation (high/low), and Credit Availability (high/low). As these conditions affect the availability to fund advertising efforts, high Fuel Cost, high Regulation, and low Credit Availability represents the worst case scenario. The agents next determine the advertising level to set based on the values of the environmental agents. Frontier relies heavily on advertising so the model allows them to set the property Advertising to high if two out of the three values are favorable. United, on the other hand, requires all three values to be favorable in order to set Advertising to high.

Starting at beginning of Week 12 of the simulation (i.e. end of the first quarter) and reoccurring every 12 weeks thereafter, the Frontier and United agents calculate the current market share to date in the simulation and compare to a predetermined minimum desired level (Frontier $=16 \%$, United $=21 \%$ ). We arbitrarily selected these amounts based on historic market share percentages. Should the current market share fall below the threshold, the airline agent re-evaluates the advertising level based on the environmental agent values at that time (same procedure as at Time 0 ). No action happens if the market share remains above threshold. The environmental factors affecting the airline advertising decisions will now be examined.

4.3.4.4 Environmental factors. Several critical economic and environmental factors severely impact the ongoing operations and financial stability of Frontier as well as all carriers in the airline industry and therefore, have been included in the model. First, fuel costs represent the single largest individual operating expense item for Frontier (29.0\% in 2007 and $27.9 \%$ in 2006) (Frontier Airlines Holdings, 2006, 2007). Over the 4-year period 2004-2007, fuel costs rose 103.8\% and the trend is expected to continue with little ability to pass cost on to consumers. Second, subjection to heavy federal regulation has resulted in operating cost increases in the past and may do so in the future. For example, President Bush signed the Stabilization Act in to law in 2001 that federalizes most civil aviation security and requires the implementation of certain security measures by airlines and airports such as screening all passenger baggage by the Transportation Security Administration (TSA). Funding for these security activities comes from a $\$ 2.50$ per enplanement ticket tax and the TSA can impose additional fees on air carriers as the agency deems necessary 
(Frontier Airlines Holdings, 2006). In the 'Risk Factors' section of their respective 2006 annual reports, both airlines acknowledge extensive government regulation could increase operating costs and affect the ability to conduct business. To the extent costs of measures such as the Stabilization Act cannot be passed on to consumers, airlines face significant financial challenges. Finally, availability of credit in the broader economic market or lack thereof poses a great risk to airlines in several respects. When credit is scarce and the economy suffers, consumers tend to tighten their purse strings and travel less. Creditors also become more stringent and wary of extending additional credit. As noted in their 2006 annual reports, both Frontier and United suffer from very little available credit and must rely on existing cash and generation of operating cash flows to support operating activities. Another potential consequence of tighter credit markets, commonly referred to as the 'credit-card holdback', affects the airline industry specifically. Airlines contract with one or more (usually no more than three) credit card companies to process their customers' credit purchases. Typically, credit card processors immediately pass along the majority of proceeds to airlines with the remainder held back until the passenger completes the flight. However, processors have the right at any time to raise the amount held until completion of service should they feel at risk of an airline discontinuing service thus transferring responsibility to them for the money (Atlanta Journal-Constitution, 2008). This sort of event could adversely affect the cash flow position of an airline, particularly those dependent on operating cash to survive.

Accordingly, the simulation model contains external agents that represent fuel costs, federal regulation, and credit availability. In actuality, the agents are proto-agents rather than full-fledge agents. The behavior of proto-agents affect other agents but do not act and react to changes to or made by other agents. The environmental agents in this study randomly start with either a high or low value then have the potential to adjust (randomly) on a predetermined schedule: Fuel Cost has a $60 \%$ chance of being set to high at Time 0 and every 4 weeks, Regulation $60 \%$ chance at Time 0 and every 12 weeks, and Credit Availability $50 \%$ at Time 0 and every 4 weeks.

4.3.4.5 Design specifications and model functionality. Using the design principles derived from the CAIO theory presented earlier, we developed an ABM of the Frontier Airlines market as an illustration of the type of continuous auditing application an auditor can realistically develop as a tool in the analysis of a client's ongoing financial viability. We strived to maintain simplicity in the model by focusing on the factors that provide the greatest impact. The model contains agents representing consumers, airlines, and environmental factors that act and react to the behaviors of each other in a simulated economy.

Midgley et al. (2007) recommend (1) publishing detailed specifications and programming code, (2) enlisting the assistance of programming experts to inspect and correct code implementation of the specifications, (3) subjecting the model to destructive testing, and (4) empirically validating the model against real data. In this vein, Table 3 proposes a set of design specifications for the ABM and Table 5 compares the functionality built into the model to these specifications. As previously noted, we enlisted the assistance of an ABM programming expert to evaluate the correctness of the coding as well as the implementation of design specifications and intended functionality. During initial model testing both we and the external expert executed the model numerous times to assess the robustness of the model to extreme parameter values. The next section presents the results of the model simulation and subsequent financial statement analysis of projected 2007 operating results for Frontier Airlines to the actual 2007 results.

\subsection{Simulation results and financial statement analysis}

\subsubsection{Test design}

The ABM represents a simulation of the 2007 airline market in which Frontier Airlines operates. The goal of the model entails generating a market share percentage for Frontier that can be incorporated into an overall financial analysis of the company. Determination of market share percentage helps derive passenger revenue (an airline's primary source of income) that is included 
Table 5 Model functionality

\begin{tabular}{l}
\hline \hline Design specification \\
\hline 1. The simulation will consist of consumers seeking \\
services that meet their individual preferences \\
and multiple airlines that attempt to gain market \\
share through advertising toward those \\
preferences \\
The users of the simulation (auditors and \\
organizational management) work together to \\
understand the potential impacts of interactions \\
between the airline, consumers, and external \\
elements on future states of the airline. The \\
knowledge gained allows users to manage \\
uncertainty and provide more accurate \\
information about the ongoing viability of the \\
organization-all in the best interests of \\
organizational stakeholders
\end{tabular}

2. Consumers' purchasing behavior will be dependent upon past purchasing behavior and past experiences. Airlines will adjust advertising based on consumer behavior as well as changes in general economic and other external factors. Both groups of agents will retain knowledge of past transactions in memory that will affect future behavior

The resulting number of passengers served on an annual basis as provided by the simulation will assist the auditors in their going concern opinion as well as offer insight into the inner workings of the economic system, creating knowledge for all salient stakeholders

3. Salient stakeholders in the airline include shareholders, organizational management, consumers, employees, trading partners, and auditors. Ongoing viability of the organization is critical to the future of all these groups. The simulation is designed to support the going concern assessment by the auditors in order to understand conditions that may have an imminent impact on the organization

4. Consumers, airlines, and external environmental elements interact in a mock economy
Model functionality

The agent-based model consists of consumer agents that decide to travel (or not) on a weekly basis. Airline choices are dependent upon past experience with each of the airlines as well as exposure to advertising and promotion efforts by the airlines. Airline agents try to retain existing customers and gain additional market share through advertising

Users of the model can alter consumer preferences, advertising levels, and environmental factors in order to evaluate the effects of differing scenarios. The knowledge gained can assist in judging the ongoing viability of the organization

The agent-based model consists of consumer agents that decide to travel (or not) on a weekly basis. Airline choices are dependent upon past experience with each of the airlines as well as exposure to advertising and promotion efforts by the airlines. After each trip, consumer agents update memory with the most recent airline choice and trip experience. Airline agents try to retain existing customers and gain additional market share through advertising provided the current state of environmental factors does not restrict cash available for advertising expenditures

The model tracks each consumer purchase over 52 'ticks' or weeks and provides market share data for each airline over the course of the simulated year. Auditors can detect a general trend in market share and use the data to calculate revenue for the prospective financial statements to be used in the going concern opinion

Market share data calculated in the model simulation can be used to derive annual passenger revenue, the key driver to airline financial performance. Auditors can develop multiple prospective income statements using model data that depict the impact of different market conditions on the airline's financial performance. These prospective statements will help determine whether the airline's operating income is sufficient to maintain ongoing operations for the upcoming year given key market factors

The agent-based model consists of consumer agents; agents for Frontier Airlines and United Airlines; and agents that represent fuel costs, federal regulation, and credit availability. The agents interact in a 52-week simulation of the airline market that Frontier Airlines services 
Table 5 (Continued)

5. The individual agents in each group (consumer, airline, environmental) possess local decisionmaking rules and preferences
Each consumer agent possesses memory that contains information about the last airline flown and the related experience (good/bad) as well as the last experience on the other two airlines, if the consumer had ever flown on them. The agent also has a strength of memory factor that dictates both how loyal the agent is (if at all) to the most recent airline as well as how susceptible the agent is to airline advertising.

The Frontier and United airline agents evaluate current environmental market conditions to periodically set their levels of advertising. In addition, the agents regularly calculate their current market share and compare to a desired amount. If the airline's market share falls below this threshold, the airline examines current environmental factors to determine if it can raise advertising levels to raise market share

The three environmental factors randomly determine their levels on a scheduled basis

The model tracks each consumer purchase over 52 'ticks' or weeks and provides market share data for each airline over the course of the simulated year. This data can be used to determine projected passenger revenue for the prospective income statement which will be used to evaluate the airline's ongoing viability

in the prospective income statement developed by the auditor to determine operating income and associated operating cash flow. As previously noted, auditors generally view operating income and operating cash flow as the foremost indicators of a company's near-term financial viability.

As the auditor's going concern opinion occurs once a year in conjunction with the annual audit report, the model simulates 1 year of Frontier's airline market. Each 'tick' represents a single week (52 total ticks) where consumers decide to travel (or not) and airline agents monitor consumer and environmental agent activity to determine their levels of advertising expenditures. Each 'run' of an ABM simulation (i.e. 52-week simulation) can generate wildly different results from any other run as local agent interactions occur and unpredictably influence the collective state of the system. A modeler must therefore not rely on a single run but examine the general trend of multiple runs (North \& Macal, 2007). We chose to execute 30 runs in succession as a 'batch' and nine batches in total differing on number of total consumers (1000, 10000 , and 100000) and states of the environmental factors (unconstrained, all set to bad, all set to good). Unfortunately, available computing power was limited and restricted analysis of a consumer market greater than 100000 . Auditors developing a similar ABM would have extensive resources to draw upon. Regarding the environmental factor settings, auditors typically wish to analyze multiple scenarios before issuing a going concern opinion. Forcing the factors to remain at certain levels facilitates examination of worst case and best case scenarios while allowing the factors to be 'free' provides a most likely scenario.

\subsubsection{Simulation results}

Across the three consumer levels (i.e. 1000, 10000 , and 100 000) with 30 runs each, Frontier's anticipated 2007 market share in the unconstrained model averaged 17.64\% (range 15.74-19.33\%) 
with United at $24.99 \%$ and Other at $57.37 \%$. Consumers switched airlines $39.69 \%$ of the time. Frontier gained $29.38 \%$ of these 'switchers' and lost $28.95 \%$, a slight net gain. Of the total Frontier trips, consumers switching to Frontier comprised $66.10 \%$, repeat passengers $33.14 \%$ (i.e. non-switchers), and new flyers $0.74 \%$.

Under the worst case scenario with both Fuel Cost and Regulation set at high and Credit Availability set at low, Frontier earned $16.03 \%$ (range 14.57-17.51\%) of the market with United at $24.84 \%$ and Other at $59.13 \%$. Consumers switched airlines $41.22 \%$ of the time. Frontier gained $27.36 \%$ of these 'switchers' and lost $27.76 \%$, a slight net loss. Of the total Frontier trips, consumers switching to Frontier comprised $70.35 \%$, repeat passengers $28.81 \%$ (i.e. non-switchers), and new flyers $0.84 \%$. Further analysis shows Frontier attracted $2.02 \%$ less switchers and retained $20.93 \%$ fewer repeat passengers in the 'bad' environment. To determine if the difference in Frontier's market share is different between the unconstrained model and the bad model, we performed an independent-samples $t$-test comparison of mean values for the two sets (three batches each with 30 records for a total $n=90$ per model). The test revealed the two sample means are statistically different $(t=14.782, p<0.01)$ indicating the inability to advertise due to poor environmental factors severely affected Frontier's ability to attract and retain consumers.

Under the best case scenario with both Fuel Cost and Regulation set at low and Credit Availability set at high, Frontier earned $21.25 \%$ (range 20.35-22.63\%) of the market with United at $20.91 \%$ and Other at $57.84 \%$. Consumers switched airlines $39.74 \%$ of the time. Frontier gained $32.43 \%$ of these 'switchers' and lost $30.81 \%$, a weighty net gain. Of the total Frontier trips, consumers switching to Frontier comprised $60.66 \%$, repeat passengers $38.68 \%$ (i.e. non-switchers), and new flyers $0.66 \%$. Further analysis shows Frontier attracted 3.06\% more switchers and retained $40.88 \%$ more repeat passengers in the 'good' environment. To determine if the difference in Frontier's market share is different between the unconstrained model and the good model, we performed an independent-samples $t$-test comparison of mean values for the two sets (three batches each with 30 records for a total $n=90$ per model). The test revealed the two sample means are statistically different $(t=-35.388, p<0.01)$ indicating the ability to advertise due to better environmental factors positively affected Frontier's ability to attract and retain consumers.

The Bureau of Transportation Statistics reported that Frontier earned $17.46 \%$ of the market share for the routes the company serviced during 2007 with United at $32.20 \%$ and Other at $50.34 \%$ (Bureau of Transportation Statistics, 2008). After three batches and 90 runs, the model estimated only $0.18 \%$ higher than Frontier's actual but underestimated United by $7.21 \%$ and overestimated Other by $7.03 \%$. United's activity on these routes fluctuates significantly rising from a $23 \%$ market share in 2006 to $32 \%$ in 2007 then falling again to $25 \%$ in 2008 as the company acquires/sells gates and adds/subtracts flights. Given the focus of the model is to estimate Frontier's status in the marketplace, these results seem reasonable.

Table 6 highlights the results of the three models. Using the estimated market share from the unconstrained model, we will now create a prospective income statement to estimate operating income and operating cash flow in order to conduct a mock going concern analysis.

As discussed previously, some auditors use statistical models (e.g. Altman $Z$-score) while others perform analytical procedures of key financial numbers to assess the ongoing viability of audit clients per SAS 59 requirements (i.e. the going concern opinion). Inherent problems arise with the structure and use of the more common statistical models hence the application of the alternative method that allows greater auditor judgment and reliance on expertise. Analytical procedures are comparisons of unaudited financial data with expected results (Glover et al., 2000). These procedures occur primarily at the beginning of an audit to plan the nature, timing, and extent of testing (American Institute of Public Accountants, 1998). Significant fluctuations between client data and auditor expectations signal increased risk of material error for a particular accounting area (e.g. valuation of accounts receivable and estimated bad debts). Auditors perform essentially the same process at the end of the audit to develop expectations of the financial statements for the upcoming year, also known as prospective financial statement forecasts. The prospective information (most notably the estimated operating income and operating cash flow) form the basis 
Table 6 Comparison of model simulation results

\begin{tabular}{lllc}
\hline \hline & $\begin{array}{l}\text { Unconstrained } \\
\text { model (\%) }\end{array}$ & $\begin{array}{l}\text { Bad } \\
\text { environment (\%) }\end{array}$ & $\begin{array}{l}\text { Good } \\
\text { environment (\%) }\end{array}$ \\
\hline Frontier market share & 17.64 & 16.03 & 21.25 \\
United market share & 24.99 & 24.84 & 20.91 \\
Other market share & 57.37 & 59.13 & 57.84 \\
Consumer switching (\%) & 39.69 & 41.22 & 39.74 \\
Repeat passengers (of total Frontier) & 33.14 & 28.81 & 38.68 \\
Passengers switching to Frontier (of total Frontier) & 66.10 & 70.35 & 60.66 \\
New flyers (of total Frontier) & 0.76 & 0.84 & 0.66 \\
Change in retention & na & -20.93 & +40.88 \\
Change in attracting switchers to Frontier & na & -2.02 & +3.06 \\
\hline \hline
\end{tabular}

for the auditor's going concern opinion. Drawing on results from the ABM developed in this study and historical trend analyses, we briefly discuss the comparison of prospective statements we prepared for 2007 to Frontier's audited financial results.

The process to create prospective financial statements consists of first identifying the key account balances and financial statement line items that comprise the majority of each statement. Once determined, the auditor develops expectations of each item then assembles them together in the appropriate financial statement format. Expectations result from analysis of historical financial data, anticipated actions by management, industry factors that may affect the major financial statement line items. For this exercise, we chose to analyze key income statement line items to project Frontier's 2007 operating income and operating cash flow. Revenues represent the most important and most difficult component of the income statement to anticipate. So many interrelated factors come in to play that potentially could affect the business a company earns that the human mind has a difficult time assimilating the interactions. Enter the computer simulation.

The Frontier ABM produces the key driver of revenue for the airline as consumer passenger volume represents $97 \%$ of Frontier's 2006 revenue. Therefore, estimation of two components is needed: (1) number of passengers and (2) the revenue generated per passenger. To develop the estimate of 2007 passenger revenue, we first calculated a total market that Frontier competed in by utilizing the data reported by BTS of the total number of passengers traveling the routes Frontier serviced in 2006, an estimated 50.75 million travelers. After estimating a total market we determined a proportion to assign to Frontier. The unconstrained model of the ABM generated a $17.64 \%$ Frontier market share. Multiplying the simulated market share percentage times the projected total market results in an estimated 8.95 million passengers for Frontier. However, a discrepancy exists between the amount of passengers BTS reports for Frontier in 2006 and the amount reported in the financial statements. Of the 40.78 million passengers traveling Frontier routes in 2006, Frontier earned the business of 7.47 million (18.32\%) according to BTS. The 2006 financial statements reported 8.68 million revenue passengers carried. The discrepancy lies in the various agreements with other airlines such as code-sharing and outsourcing of certain routes. BTS reports these passengers under the airline actually operating the flight, not the company whose financial statements include these passengers. To reflect the difference, we adjusted the 8.95 million passengers estimated using BTS figures by $+16 \%$ (the amount BTS differed from the financial statements in 2006) resulting in a projection of 10.38 million Frontier passengers. To estimate the second component necessary to project passenger revenue, we calculated the revenue per passenger for the years 2003-2006. Using the average change from year-to-year for the period $(-0.35 \%)$, we calculated $\$ 111.58$ of revenue to be generated by each of the 10.38 million passengers. Projected passenger revenue for 2007 is $\$ 1.16$ billion. For the other key items in the model we used more linear analysis based on historical relationships as those components, 
particularly costs and expenses, typically have direct relationships to the amount of revenue earned. The first numerical column in Appendix $\mathrm{C}$ presents the projected operating income statement and operating cash flow.

So, how well did the prospective financial statements developed using the ABM simulation compare to Frontier's actual, audited financial data for 2007? As previously noted, the ABM derived a $17.64 \%$ market share for Frontier whereas the actual was $17.46 \%$. Frontier reported 10.04 million passengers carried (3.33\% less than prospective) and $\$ 1.17$ billion revenue $(2.19 \%$ less). However, the revenue generated per passenger of $\$ 112.71$ exceeded that in the prospective financial statements by $1.01 \%$. Furthermore, actual operating expenses were $\$ 1.18$ billion $(2.27 \%$ less) providing a higher actual operating income (a net loss of $\$ 9.83$ million). Frontier appears to have further streamlined expenses to become even more efficient. Frontier generated positive operating cash flow of $\$ 23.23$ million which is $5.14 \%$ less than prospective and a higher percentage relative to operating revenues $(-236.19 \%)$ meaning the company squeezed out more cash per revenue dollar than previous years. Based on actual operating income and the 3-year average factor of $-205.15 \%$ included in the prospective financial statements, the expectation would be the generation of $\$ 20.18$ million of free cash. On the key figures of operating income and operating cash flow, Frontier slightly outperformed the prospective financial statements. Overall, the ABM helped produce prospective financial statements fairly close to actual 2007 operations. Appendix C provides a comparison of prospective financial information to actuals.

This section presented an instantiation of the CAIO theory through an agent-based simulation model to assist with the auditor's going concern opinion for Frontier Airlines. The design of the model adhered to prescribed guidelines and best practices for design science, simulation, and agent-based modeling. The design specifications presented were based on CAIO design principles and acted as the guide for developing the types of agents, their behavior, and interaction with other agents. Multiple executions of the simulation model produced an expected market share for Frontier Airlines used to develop prospective financial information for 2007 necessary to issue a going concern opinion for the viability of Frontier during the next year. The ABM built from the underlying theories of complexity science and SIS helped develop prospective financial information that estimated actual results fairly well and showed Frontier consistently produces positive operating cash in spite of continued net operating losses. The final section of this study summarizes the study as a whole and discusses the implications of continuous auditing in a complex business environment.

\section{Discussion and conclusion}

Countries around the world have begun to require mandatory XBRL reporting of financial information. The progression to more available and readable financial information helps fuel the fire for continuous auditing and assurance of said information. Although the large international public accounting firms have not yet incorporated continuous auditing into their practices, they recognize the need to develop and explore innovative tools and methodologies to support continuous auditing in the future. The most obvious evidence of this is the support of the Continuous Auditing Research Lab at Rutgers University by 'Big Four' accounting firm KPMG. KPMG and the other Big Four accounting firms (PricewaterhouseCoopers, Deloitte, and Ernst \& Young) also are active participants in the World Continuous Auditing \& Reporting Symposia that are held twice a year (once in the United States and once at an international site) to bring together accounting researchers, managers and auditing practitioners to advance continuous auditing capabilities. To date, these efforts have been ad hoc, with little effort to develop an underlying design theory or the diverse needs of the various stakeholders.

CA applications and systems need to be developed to meet the diverse needs of the assurers (public accounting firms), company management producing the financial statements, shareholders, consumers, regulatory authorities, financial market participants, creditors, etc. This network of stakeholders interacts with each other as well as members in other extended networks. 
CA systems therefore must be designed to support constantly changing environments, generate new knowledge, and provide decision support in an increasingly complex and connected world.

This research study addresses the lack of an underlying system design theory and comprehensive view with the goal to determine how CA systems should be designed to produce knowledge that benefits auditors, clients, and society as a whole. To accomplish this, we first developed a comprehensive, system design theory called the CAIO theory based on the fundamentals of complexity theory and Churchman's (1971) SIS. Next, we established a set of associated design principles for CA systems. Applying these design principles, we then illustrated the general model by creating an agent-based simulation model of the Frontier Airlines market that includes agents representing Frontier, key competitors, consumers, and the general economic environment.

Using the Frontier ABM as a decision support system, we conducted a mock going concern analysis of the ongoing viability of Frontier by incorporating the airline's share of the market (per the $\mathrm{ABM}$ ) as an input into the construction of 2007 prospective financial statements - much the same as the company's auditors perform each year. Comparison of the simulation results and prospective financial statements to actual operating results indicated the ABM developed from the CAIO theory performed well as a potential tool for continuous auditing of a company's financial health. The $17.64 \%$ market share generated by the unconstrained version of the ABM produced a projected 10.38 million Frontier passengers in 2007 and related passenger revenue of $\$ 1.15$ billion. After developing estimates for other key line items of the income statement based on historical company trends, the prospective financial statements forecasted an \$11.94 million operating loss and \$24.49 million operating cash inflow. For 2007, Frontier earned $17.46 \%$ of the market, serviced 10.04 million passengers, earned $\$ 1.13$ billion in passenger revenue, and reported a $\$ 9.83$ million operating loss and $\$ 23.23$ million operating cash inflow. With the assistance of the ABM based on the CAIO theory, the prospective financial statements offered a conservative estimate of the future financial performance of Frontier Airlines. An actual going concern opinion based on this model would have been slightly guarded (appropriately so) and adhered to one of the core tenets accounting and auditing that of conservatism. An adverse going concern opinion can be a self-fulfilling prophecy that may ruin a company's future. Auditors must be extraordinarily cautious.

In practice, auditors can develop similar models to the ABM developed in this study based on their intimate knowledge of their clients and respective industries that can assist in the going concern opinion. Note, however, the going concern opinion represents the final stage of the audit. The opinion looks forward using the most recent audited financial statement information that depicts the current state of the company (i.e. the balance sheet) and the most recent performance (i.e. income statement). Should the financial information contain material errors or are fraudulent, the auditor's going concern opinion will be built on a faulty foundation and thus less likely to provide an accurate assessment of the future state of the client. The use of independent data such as oil prices, industry trends, etc. in an ABM can reduce the reliance on internal client information that may be biased or incorrect and help produce a higher quality opinion. Furthermore, as the movement of continuous reporting progresses the market will demand CA of reported financial information. Auditors can develop their models to 'sweep in' current/updated information to provide more frequent and accurate opinions of the ongoing viability of their clients, create more elaborate models that build expectations for all the key financial statement line items rather than just the single one in illustrated in this study (i.e. passenger revenue), and ultimately meet the knowledge needs of associated stakeholders.

As continuous reporting becomes more commonplace academics and practitioners will need to address the functionality and ramifications of a CA environment in a business world that appears to be 'flattening' and becoming more interconnected as evidenced by the Great Credit Crisis of 2008 currently affecting the entire global economic system. Systems will inevitably be created. How will they be designed? Will they serve needs of humanity, the ultimate stakeholder? Only time will tell. We humbly offer a starting point. For now, the complexity movement in the accounting and IS disciplines is under way and, as CASs infamously do, the movement will feed upon the 
energy of itself and the environment to evolve exponentially in a nonlinear manner. The future is unknown, but we are confident an underlying pattern exists suggesting a bright future lies ahead for complexity research in accounting and IS, starting with CA.

\section{Appendix A: A taxonomy of inference}

(Brenner \& Werker, 2007)

Table A1 Inferring results in simulation models

\begin{tabular}{|c|c|c|c|c|}
\hline \multirow[b]{2}{*}{ Approach } & \multirow[b]{2}{*}{ Building the model } & \multirow[b]{2}{*}{ Conducting the runs } & \multicolumn{2}{|l|}{ Analysing the results } \\
\hline & & & Usually done & Possible \\
\hline Conventional & $\begin{array}{l}\text { Rather hypothetical, } \\
\text { specific }\end{array}$ & $\begin{array}{l}\text { Usually one } \\
\text { specification run }\end{array}$ & Characteristics study & Comparison \\
\hline Microsimulations & Empirical, specific & $\begin{array}{l}\text { One specification } \\
\text { run }\end{array}$ & $\begin{array}{l}\text { Prediction, } \\
\text { characteristics } \\
\text { study, some } \\
\text { comparison }\end{array}$ & - \\
\hline Bayesian & $\begin{array}{l}\text { Hypothetical, } \\
\text { general }\end{array}$ & $\begin{array}{l}\text { Many specifications } \\
\text { run (sometimes } \\
\text { Monte-Carlo) }\end{array}$ & Comparison & $\begin{array}{l}\text { Characteristics } \\
\text { study, prediction }\end{array}$ \\
\hline History friendly & $\begin{array}{l}\text { Rather empirical, } \\
\text { specific }\end{array}$ & $\begin{array}{l}\text { One specification } \\
\text { run, with sensitivity } \\
\text { analysis }\end{array}$ & $\begin{array}{l}\text { Comparison, } \\
\text { characteristics } \\
\text { study }\end{array}$ & - \\
\hline Abductive & $\begin{array}{l}\text { As empirical as } \\
\text { possible, as general } \\
\text { as necessary }\end{array}$ & $\begin{array}{l}\text { Many specification } \\
\text { runs (Monte-Carlo) }\end{array}$ & $\begin{array}{l}\text { Comparison, } \\
\text { characteristics } \\
\text { study, } \\
\text { categorization }\end{array}$ & Prediction \\
\hline
\end{tabular}

\section{Appendix B: List of model assumptions}

1. Consumers travel only once per week and experiences (good or bad) reflect a single trip (one-way or round).

2. New travelers comprise $0-10 \%$ of all travelers.

3. A large majority of travelers encounter a bad experience (randomized range $=70-100 \%$ ).

4. Once assigned a last airline and associated experience $(\operatorname{good}=0$ or $\mathrm{bad}=1)$ at Time 0 , travelers will be assigned an experience for the other airlines regardless if they have flown that airline. A value of 1 represents either an actual bad experience or no experience at all.

5. Travelers with a good last experience stay loyal to the airline for the next trip.

6. Less frequent travelers have a higher chance to switch airlines after experiencing a bad trip than travelers who travel more frequently.

7. Advertising levels for Frontier Airlines are more crucial and have a larger effect on consumers than that for United and the collective Other airlines group.

8. Airlines evaluate advertising levels for adjustment every 2 weeks and once a quarter (every 12 weeks) after identifying current market share.

9. Airlines review their current market share each quarter and adjust advertising levels based on a predetermined desired market share.

10. Due to inflation, fuel costs have a higher likelihood of rising and thus a greater chance to be set at high in the model.

11. Due to the volatility in the world today (i.e. terrorism), the cost to adhere to federal regulation has a higher likelihood of rising and thus a greater chance to be set at high in the model. 
12. An even chance exists $(50-50 \%)$ that credit availability will be lowered when creditors evaluate the creditworthiness of airlines.

13. Environmental agents potentially can change values on a scheduled basis: Fuel Cost every 4 weeks, Regulation every 12 weeks, and Credit Availability every 4 weeks.

14. A simulated market with 1000; 10000; and 100000 consumer agents accurately represents the broader Frontier airline market ( $\sim \$ 41$ million passengers in 2006).

\section{Appendix C: Comparison of prospective financial information to 2007 Actual Data}

\begin{tabular}{lccc}
\hline \hline Financial statement item (in \$ thousands) & Projected (2007) & Actual (2007) & Difference (\%) \\
\hline Passengers & 10384 & 10039 & -3.33 \\
Revenues & & & \\
$\quad$ Passenger & 1158697 & 1131466 & \\
$\quad$ Cargo & 6529 & 6880 & \\
$\quad$ Other & 31913 & 32603 & -2.19 \\
Total revenue & 1197139 & 1170949 & \\
Expenses & & & \\
$\quad$ Fuel costs & 352905 & 343082 & -2.27 \\
$\quad$ Promotion and sales & 117783 & 115536 & -21.37 \\
$\quad 738387$ & 723033 & -5.14 \\
Tother & 1209075 & 1181651 & \\
Operating income & 11936 & 9834 & 23227 \\
Operating cash flow & 24486 & & \\
\hline \hline
\end{tabular}

\section{References}

Altman, E. I. 1968. Financial ratios, discriminant analysis and the prediction of corporate bankruptcy. Journal of Finance 23(4), 589-609.

American Institute of Public Accountants. 1998. Analytical Procedures, Statement on Auditing Standards No. 56. AICPA.

American Institute of Public Accountants. 2008. AICPA Code of Professional Conduct: Article II-The Public Interest. AICPA (Available from http://www.aicpa.org/about/code/et_section_53_article_ ii_the_public_interest.html).

Anderson, P. 1999. Complexity theory and organization science. Organization Science 10(3), 216-232.

Anufriev, M. \& Hommes, C. 2009. Evolution of market heuristics. The Knowledge Engineering Review 27(2), $255-271$.

Atlanta Journal-Constitution. 2008. Credit card processors can clip airlines' wings. DallasNews.com (Available from http://www.dallasnews.com/sharedcontent/dws/bus/industries/airlines/stories/DN-airlines_ 14bus.State.Edition1.96500a.html).

Avgerou, C. \& McGrath, K. 2007. Power, rationality, and the art of living through socio-technical change. MIS Quarterly 31(2), 293-315.

Avison, D. E., Wood-Harper, A. T., Vidgen, R. T. \& Wood, J. R. G. 1998. A further exploration into information systems development: the evolution of Multiview 2. Information Technology \& People 11(2), 124-139.

Benbasat, I. \& Zmud, R. W. 1999. Empirical Research in Information Systems: the Practice of Relevance. MIS Quarterly 23(1), 3-16.

Benbya, H. \& McKelvey, B. 2006. Toward a complexity theory of information systems development. Information Technology and People 19(1), 12-34.

Bonabeau, E. 2002. Predicting the unpredictable. Harvard Business Review 80(3), 109-116.

Brenner, T. \& Werker, C. 2007. A taxonomy of inference in simulation models. Computational Economics 30(3), 227-244.

Bureau of Transportation Statistics. 2008. T-100 Domestic Market (All Carriers). Bureau of Transportation Statistics. 
Carugati, A. 2008. Information systems development activities and inquiring systems: an integrating framework. European Journal of Information Systems 17, 143-155.

Casti, J. L. 1997. Would-be worlds: how simulation is changing the frontiers of science. Wiley.

Cederman, L. E. 1997. Emergent Actors in World Politics: How States and Nations Develop and Dissolve. Princeton University Press.

Chapman, G. P. 1985. The Epistemology of Complexity and Some Reflections on the Symposium: The Science and Praxis of Complexity, Montpellier. The United Nations University.

Choi, T. Y., Dooley, K. J. \& Rungtusanatham, M. 2001. Supply networks and complex adaptive systems: control versus emergence. Journal of Operations Management 19(3), 351-366.

Churchman, C. W. 1971. The Design of Inquiring Systems: Basic Concepts of Systems and Organization. Basic Books.

Cilliers, P. 1998. Complexity and Postmodernism: Understanding Complex Systems. Routledge.

City and County of Denver, Colorado Municipal Airport System. 2006. Annual financial report (Available from http://www.flydenver.com/diabiz/stats/financials/reports/2006_finrpt.pdf).

Courtney, J. F. 2001. Decision making and knowledge management in inquiring organizations: toward a new decision-making paradigm for DSS. Decision Support Systems 31(1), 17-38.

Courtney, J. F., Croasdell, D. T. \& Paradice, D. B. 1998. Inquiring organizations. Australian Journal of Information Systems 6(1), 3-15.

Courtney, J. F., Merali, Y., Paradice, D. B. \& Wynn, E. 2008. On the Study of Complexity in Information Systems. International Journal of Information Technologies and the Systems Approach 1(1), 37-48.

Cox, C. 2008. Speech by SEC Chairman: 'The SEC Agenda for 2008'. US Securities and Exchange Commission (Available from http://www.sec.gov/news/speech/2008/spch020808cc.htm).

Dastani, M. \& Gomez-Sanz, J. J. 2005. Programming multi-agent systems. The Knowledge Engineering Review 20(2), 151-164.

Dooley, K. J. 1997. A complex adaptive systems model of organization change. Nonlinear Dynamics, Psychology, and Life Sciences 1(1), 69-97.

Dugan, M. T. \& Zavgren, C. V. 1988. Bankruptcy prediction research: a valuable instructional tool. Issues in Accounting Education 1, 48-65.

Dyslin, A. 2007. A Hops Crisis Looms: Cost of Beer Could Rise. The Free Press (Available from http:// www.mankato-freepress.com/local/local_story_319225135.html).

Epstein, J. M. \& Axtell, R. 1996. Growing Artificial Societies: Social Science from the Bottom Up. Brookings Institution Press.

Frontier Airlines Holdings Inc. 2006. Annual Report. Retrieved on May 3, 2014 and available at http:// www.sec.gov/edgar.shtml\#. U2UvhlfizYM.

Frontier Airlines Holdings Inc. 2007. Annual Report. Retrieved on May 3, 2014 and available at http:// www.sec.gov/edgar.shtml\#. U2UvhlfizYM.

Giddens, A. 1984. The Constitution of Society. Cambridge, England.

Glover, S. M., Jiambalvo, J. \& Kennedy, J. 2000. Analytical procedures and audit-planning decisions. Auditing: A Journal of Practice \& Theory 19(2), 27-46.

Greenwood, D. 2007. From market to non-market: an autonomous agent approach to central planning. The Knowledge Engineering Review 22(4), 349-360.

Grice, J. S. \& Dugan, M. T. 2001. The limitations of bankruptcy prediction models: some cautions for the researcher. Review of Quantitative Finance and Accounting 17(2), 151-166.

Grice, J. S. \& Ingram, R. W. 2001. Tests of the generalizability of Altman's bankruptcy prediction model. Journal of Business Research 54(1), 53-61.

Hall, D. J. \& Davis, R. A. 2007. Engaging multiple perspectives: a value-based decision-making model. Decision Support Systems 43(4), 1588-1604.

Hall, D. J. \& Paradice, D. 2005. Philosophical foundations for a learning-oriented knowledge management system for decision support. Decision Support Systems 39(3), 445-461.

Hall, D. J., Paradice, D. B. \& Courtney, J. F. 2003. Building a theoretical foundation for a learning-oriented knowledge management system. Journal of Information Technology Theory and Application 5(2), 63-84.

Harris, J. \& Uncles, M. 2007. Modeling the repatronage behavior of business airline travelers. Journal of Service Research 9(4), 297-311.

Hevner, A. R., March, S. T., Park, J. \& Ram, S. 2004. Design science in information systems research. MIS Quarterly 28(1), 75-105.

Hoffman, W. M. \& Rowe, M. 2007. The ethics officer as agent of the board: leveraging ethical governance capability in the post-Enron Corporation. Business and Society Review 112(4), 553-572.

Keen, P. G. W. \& Sol, H. G. 2007. Rehearsing the Future: Building Decision Agility through Decision Enhancement Services. Delft University Press.

Kim, R. M. \& Kaplan, S. M. 2006. Interpreting socio-technical co-evolution: applying complex adaptive systems to IS engagement. Information Technology and People 19(1), 35-54. 
Kogut, B. \& Zander, U. 1992. Knowledge of the firm, combinative capabilities, and the replication of technology. Organization Science 3(3), 383-397.

Laurent, G. \& Koch, C. 1999. Complexity and the nervous system. Science 284, 96-98.

Law, A. M. 2005. How to build valid and credible simulation models. In Proceedings of the 37th Conference on Winter Simulation, 58-66 (December 4-7, Orlando, FL).

Linden, L. P., Kuhn, J. R., Parrish, J., Richardson, S. M., Adams, L. A., Elgarah, W. \& Courtney, J. F. 2007. Churchman's inquiring systems: kernel theories for knowledge management. Communications of the Association for Information Systems 20, 836-871.

Luoma, M. 2006. A play of four arenas: how complexity can serve management development. Management Learning 37(1), 101-123.

Markus, M. L., Majchrzak, A. \& Gasser, L. 2002. A design theory for systems that support emergent knowledge processes. MIS Quarterly 26(3), 179-212.

Mason, R. B. 2007. The external environment's effect on management and strategy: A complexity theory approach. Management Decision 45(1), 10-28.

Mason, R. O. \& Mitroff, I. I. 1973. A program for research on management information systems. Management Science 19(5), 475-488.

McKee, T. E. 2003. Rough sets bankruptcy prediction models versus auditor signalling rates. Journal of Forecasting 22(8), 569-586.

Merriam-Webster Inc. 2008. Merriam-Webster's Online Dictionary. Merriam-Webster Inc. (Available from http://www. merriam-webster.com/dictionary/complex).

Midgley, D., Marks, R. \& Kunchamwar, D. 2007. Building and assurance of agent-based models: an example and challenge to the field. Journal of Business Research 60(8), 884-893.

Mikulecky, D. C. 1999. Definition of Complexity. Retrieved on May 3, 2014 and available at: http:// www. people.vcu. edu/ mikuleck/ONo20COMPLEXITY.html.

Mitchell, R. K., Agle, B. R. \& Wood, D. J. 1997. Toward a theory of stakeholder identification and salience: defining the principle of who and what really counts. Academy of Management Review 22(4), 853-886.

Mitroff, II \& Linstone, H. A. 1993. The Unbounded Mind: Breaking the Chains of Traditional Business Thinking. Oxford University Press.

North, M. J. \& Macal, C. M. 2007. Managing Business Complexity: Discovering Strategic Solutions With Agent-Based Modeling And Simulation. Oxford University Press.

Ohlson, J. A. 1980. Financial ratios and the probabilistic prediction of bankruptcy. Journal of Accounting Research 18(1), 109-131.

Parrish, J. L. Jr. 2008. Sensemaking and Inquiring Systems: Towards a Weickian Inquiring System, PhD dissertation, University of Central Florida.

Reitsma, F. 2003. A response to simplifying complexity. Geoforum 34(1), 13-16.

Richardson, S. M. \& Courtney, J. F. 2004. A Churchmanian theory of knowledge management system design. Paper read at Proceedings of the 37th Hawaii International Conference on System Sciences, January 5-8, Big Island, HI, USA.

Richardson, S. M., Courtney, J. F. \& Haynes, J. D. 2006. Theoretical principles for knowledge management system design: application to pediatric bipolar disorder. Decision Support Systems 42(3), 1321-1337.

Richardson, S. M., Courtney, J. F. \& Paradice, D. B. 2001. An assessment of the Singerian approach to organizational learning: cases from academia and the utility industry. Information Systems Frontiers 3(1), 49-62.

Rittel, H. W. J. \& Webber, M. M. 1973. Dilemmas in a general theory of planning. Policy Sciences 4(2), $155-169$.

Rodgers, W., Hedelin, L., Housel, T. \& Kuhn, J. R. 2008. Exploratory and Exploitative Knowledge Learning by Investment Analysts. Working paper, University of California, Riverside.

Sánchez, P. J. 2006. As simple as possible, but no simpler: a gentle introduction to simulation modeling. In Proceedings of the 37th Conference on Winter Simulation, 2-10 (December 4-7, Orlando, FL).

Schein, E. 1992. Organizational Culture and Leadership. Jossey-Bass.

Siebers, P. O. \& Aickelin, U. 2007. Introduction to multi-agent simulation. In eds. Adam, F. \& Humphreys, P. Encyclopedia of Decision Making and Decision Support Technologies. IDEAS Group: 554-564.

Simon, H. A. 1996. The Sciences of the Artificial. MIT Press.

Sklar, E. \& Richards, D. 2010. Agent-based systems for human readers. The Knowledge Engineering Review 25(2), 111-135.

Srbljinovic, A. \& Skunca, O. 2003. Agent based modelling and simulation of social processes. Interdisciplinary Description of Complex Systems 1(1-2), 1-8.

Suzuki, Y. 2000. The relationship between on-time performance and airline market share: a new approach. Transportation Research Part E 36(2), 139-154.

Tesfatsion, L. 2001. Introduction to the special issue on agent-based computational economics. Journal of Economic Dynamics and Control 25(3/4), 281-293. 
Troitzsch, K. G. 2000. Approaching Agent-Based Simulation. Freshwater Integrated Resource Management with Agents (FIRMA) Meeting (June 2000).

United Air Lines Inc. 2006. Annual Report. Retrieved on May 3, 2014 and available from http://ir. unitedcontinentalholdings.com.

Van Valen, L. 1973. A new evolutionary law. Evolutionary Theory 1(1), 1-30.

Vasarhelyi, M. A. \& Halper, F. B. 1991. The continuous audit of online systems. Auditing: A Journal of Practice and Theory 10(1), 110-125.

Waldrop, M. M. 1993. Complexity: The Emerging Science at the Edge of Order and Chaos. Simon \& Schuster. Walls, J. G., Widmeyer, G. R. \& El Sawy, O. A. 1992. Building an information system design theory for vigilant EIS. Information Systems Research 3(1), 36-59.

Zhang, G., Hu, M. Y., Patuwo, B. E. \& Indro, D. C. 1999. Artificial neural networks in bankruptcy prediction: General framework and cross-validation analysis, Europ. Journal of Operational Research 116, 16.

Zimmerman, B., Lindberg, C. \& Plsek, P. 1998. Edgeware: Insights from Complexity Science for Health Care Leaders. VHA.

Zmijewski, M. E. 1984. Methodological issues related to the estimation of financial distress prediction models. Journal of Accounting Research 22(1), 59-82. 